\title{
Cladistics
}

The Willi Hennig Society

\section{Uncovering hidden coral diversity: A new cryptic lobophylliid scleractinian from the Indian Ocean}

\begin{tabular}{|r|l|}
\hline Journal: & Cladistics \\
\hline Manuscript ID & CLA-17-05-1056.R2 \\
\hline Manuscript Type: & Article \\
\hline Date Submitted by the Author: & n/a \\
\hline Complete List of Authors: & $\begin{array}{l}\text { Arrigoni, Roberto; King Abdullah University of Science and Technology, } \\
\text { Berumen, Michael; King Abdullah University of Science and Technology, } \\
\text { Stolarski, Jaroslaw; Polska Akademia Nauk, Institute of Paleobiology } \\
\text { Terraneo, Tullia; King Abdullah University of Science and Technology, } \\
\text { Benzoni, Francesca; Institut de Recherche pour le Développement, }\end{array}$ \\
\hline Keywords: & $\begin{array}{l}\text { Cladistics, Evolution, Morphology, Divergence time < Paleontology, } \\
\text { Molecular systematics < Genomics }\end{array}$ \\
\hline &
\end{tabular}




\title{
Uncovering hidden coral diversity: A new cryptic lobophylliid scleractinian from the Indian Ocean
}

\author{
Roberto Arrigoni $^{\mathrm{a}, *}$, Michael L. Berumen ${ }^{\mathrm{a}}$, Jaroslaw Stolarski ${ }^{\mathrm{b}}$, Tullia I. Terraneo ${ }^{\mathrm{a}, \mathrm{c}}$ and Francesca Benzoni ${ }^{\mathrm{d}, \mathrm{e}}$
}

${ }^{a}$ Red Sea Research Center, Division of Biological and Environmental Science and Engineering, King Abdullah University of Science and Technology, Thuwal 23955-6900, Saudi Arabia; ${ }^{b}$ Institute of Paleobiology, Polish Academy of Sciences, Twarda 51/55, PL-00-818 Warsaw, Poland; ${ }^{\circ}$ College of Marine and Environmental Science, James Cook University, Townsville, QLD 4811, Australia; ${ }^{\mathrm{d}}$ Department of Biotechnology and Biosciences, University of Milano-Bicocca, Piazza della Scienza 2, Milano 20126, Italy; ${ }^{\mathrm{e} U M R}$ ENTROPIE (IRD, Université de La Réunion, CNRS), Laboratoire d'excellence-CORAIL, centre IRD de Nouméa, New Caledonia, 101 Promenade Roger Laroque, BP A5, 98848 Noumea Cedex, New Caledonia.

*Corresponding author:

E-mail address: roberto.arrigoni@kaust.edu.sa

Keywords: evolution, phylogeny, systematics

Running title: A new cryptic coral genus

\begin{abstract}
Extant biodiversity can easily be underestimated by the presence of cryptic taxa, even among commonly observed species. Scleractinian corals are challenging to identify because of their ecophenotypic variationplasticity and morphological plasticity the occurrence of cryptic speciation. Here, we described a new cryptic lobophylliid genus and species Paraechinophyllia variabilis gen. nov., sp. nov., which is morphologically indistinguishable-similar to from Echinophyllia aspera and E. orpheensis. The new taxon occurs in Mayotte Island, Madagascar, the Gulf of Aden, and the Red Sea. Six molecular markers (COI, 12S, ATP6-NAD4, NAD3-NAD5, histone H3, and ITS) and 46 morphological characters at three different levels (macromorphology, micromorphology, and microstructure) were examined. The resulting molecular phylogeny reconstruction showed that Paraechinophyllia gen. nov. represents a distinct group within theef Lobophylliidae that diverged from the lineage leading to Echinophyllia and Oxypora in the Early Miocene, approximately 21.5 million years ago. The morphological phylogeny reconstruction clustered Paraechinophyllia gen. nov., Echinophyllia, and Oxypora together in a single clade.and Aa sole morphological character, calice relief, discriminated Paraechinophyllia gen. nov. from the latter two genera, suggesting that limited morphological variation has occurred over a long period. These results highlight the importance of cryptic taxa in reef corals, with implications for population genetics, ecological studies, and conservation.
\end{abstract}

\section{Introduction}


Cryptic species are considered defined as two or more genetically distinct species that are erroneously classified and hidden under one species name due to their morphological similarity (Bickford et al., 2007; Fišer et al., 2018). They are-a common and evenly distributed phenomena, evenly distributeden throughout major metazoan taxa and biogeographical regions (Knowlton, 1993; Pfenninger and Schwenk, 2007), and they de-certainly affect eorrectestimates of Earth's animal diversity (Mora et al., 2011; Appeltans et al., 2012; Scheffers et al., 2012). Cryptic diversity represents a major concern in many biological fields and the accurate identification of these taxa is crucial for biodiversity conservation, management, disease monitoring, and understanding evolutionary processes that drive speciation (Chadè et al., 2008; Baird et al., 2011; Andrews et al., 2014). In the last two decades, molecular genetic techniques have facilitated the detection of genetically divergent but morphologically similar cryptic lineages (Fukami et al., 2004a; Leasi et al., 2013; Egea et al., 2016; Coleman et al., 2016). The number of these discoveries continues to increase exponentially (Pfenninger and Schwenk, 2007) and, despite the lack of morphological characters to distinguish cryptic species, advancestages in DNA taxonomy tools have enablhanced formal taxonomic descriptions based on diagnostic molecular characters (Sarkar et al., 2008; Cook et al., 2010; Jörger and Schrödl, 2013).

Species identification in scleractinian corals has been based on morphology for centuries (Veron, 2000) and represents a notoriously challenging task for ecologists and taxonomists (Kitahara et al., 2016). Extremelyhigh levels of intraspecific morphological variation, common in several coral species, have contributed to complicate the definition of species boundaries in corals and constitute a commen feature of several coral species (Veron and Pichon, 1976). Environment-induced phenotypic plasticity (Todd, 2008) and intraspecific morphological variation caused by genotype (Carlon and Budd, 2002) are typical attributes of these animals and greatly further contribute to the confusion of coral identification. In the last decade, genetic data have discoveredrevealed molecular lineages that do not correspond to taxa defined by traditional taxonomy, suggesting that evolutionary convergence of morphological structures (Fukami et al., 2004무 Gittenberger et al., 2011; Budd et al., 2012a; Arrigoni et al., 2014c), morphological stasis over long periods (Flot et al., 2011; Arrigoni et al., 2016a), and genetic exchange through introgression (Combosh and Vollmer, 2015; Suzuki et al., 2016) occur in corals. Moreover, large geographic samplings across the Indo-Pacific have demonstrated the occurrence of genetic structureing, demographic isolation, and cryptic lineages within taxa that were traditionally considered to be widespread and common in the Indo-Pacific. For example, several instances of cryptic taxa have been demonstrated discovered in Acropora (Ladner and Palumbi, 2012; Richards et al., 2016), Stylophora (Flot et al., 2011; Stefani et al., 2011; Flot et al., 2011), Pocillopora (Souter, 2010; Pinzón et al., 2013; Schmidt-Roach et al., 2013a; Gélin et al., 2017a), and Seriatopora (Bongaerts et al., 2010; Warner et al., 2015).

Lobophylliidae Dai \& Horng, 2009 is an Indo-Pacific family of common and ecologically important reef corals (Veron and Pichon, 1980; Veron, 2000). Its taxonomy and systematics have been intensively investigated using a combination of molecular and morphological data during the lastin recent years (Arrigoni et al., 2014a, b, 2015, 2016b). The family and it currently comprises is comprised of 11 genera and 54 extant species (Arrigoni et al., 2016c; Huang et al., 2016; Arrigoni et al., 2016e). A The first comprehensive molecular phylogeneticy reconstruction of the family based on two markers (COI and ITS) showed that most genera (as described by 


\section{Materials and methods}

\section{Sampling and identification}

A total of 58 scleractinian corals ascribed to Lobophylliidae were collected while SCUBA diving at IndoPacific different localities (Table 1). Sampling covered all ten molecular lineages that are currently known to be ascribed to the family (Arrigoni et al., 2014a; Huang et al., 2016) and included 45 species, each-of which represented by a sole specimen. Four of the examined species, namely Echinophyllia patula (Hodgson \& Ross, 1982), Oxypora crassispinosa Nemenzo, 1979, Lobophylliza hataii Yabe \& Sugiyama, 1936, and Lobophyllia hassi Pillai \& Scheer, 1976, were phylogenetically analysed for the first time using both molecular and morphological data in this study. A total of 13 specimens identified in the field as Echinophyllia spp. were collected from nNorthern Madagascar $(n=4)$, Mayotte Island $(n=2)$, the Gulf of Aden $(n=2)$, and the Red Sea $(n=5)$.

Each coral specimen was photographed underwater (Fig. 1), collected, and tagged., and aApproximately 2 $\mathrm{cm}^{2}$ of the-each collected colony was sampled and fixed in 95\% ethanol. The remaining material was immersed in sodium hypochlorite for 48 hours to remove all tissues, rinsed in freshwater, and air-dried for identification and microscope observations of the cleaned corallum (Figs. 2 and 3). Species--level identification was based when possible on original descriptions and type material analysis when possible. Voucher samples were deposited at the Australian Museum (AM, Sydney, Australia), the Muséum Nnational d'Histoire Nnaturelle (MNHN, Paris, France), the Institute de Recherche pour le Développement (IRD, Noumea, New Caledonia), King Abdullah University of 
Science and Technology (KAUST, Thuwal, Saudi Arabia), Naturalis Biodiversity Center (RMNH, Leiden, the Netherlands), the Seto Marine Biological Laboratory at the-Kyoto University (SMBL, Kyoto, Japan), University of Milano-Bicocca (UNIMIB, Milano, Italy), and the Western Australia Museum (WAM, Perth, Australia) (Table 1). Thin sections and SEM stubs with specimens used for microstructural observations were housed at the Institute of Paleobiology, Polish Academy of Sciences, Warsaw, Poland (ZPAL).

\section{DNA extraction and amplification}

DNA extractions were carried out with the DNeasy Blood and Tissue kit (Qiagen Inc., Hilden, Germany). Six genomic regions were amplified and used as molecular markers to infer phylogeny of Lobophylliidae: 1) the barcoding portion of the cytochrome oxidase subunit I gene (COI) $\left.)_{2}-2\right)$ a portion of the small subunit rRNA gene $(12 \mathrm{~S}) ; 3)$; the $3^{\prime}$ end of the ATP synthase subunit 6 and the 5' end of the NADH dehydrogenase subunit 4 gene (ATP6-NAD4); 4), the 3' end of the NADH dehydrogenase subunit 3 gene and the 5' end of the NADH dehydrogenase subunit 5 gene (NAD3-NAD5); 5); the histone H3 gene (histone H3); and 6), the 3' end of the $18 \mathrm{~S}$ rRNA;-; the complete ITS1, 5.8S-gene, and ITS2 genes,; and the 5' end of the 28S rRNA gene (ITS). Table 2 includes the list of primers used for amplifications. COI, histone H3, and ITS have been already used to infer | phylogenetic relationships among representatives of Lobophylliidae (Arrigoni et al. 2014a, b, 2015, 2016b) and ATP6-NAD4 has been used to define species boundaries between Echinophyllia and Oxypora species (Arrigoni et al., 2016c), while-but the $12 \mathrm{~S}$ and NAD3-NAD5 were sequenced to infer phylogenetic relationships amongfor lobophylliids for the first time in this work. All PCR products were purified with Illustra ExoStar (GE Healthcare, Buckinghamshire, UK) and directly sequenced in forward and reverse directions using an ABI 3130xl Genetic Analyzer (Applied Biosystems, Carlsbad, CA, USA). We did not find double peaks or ambiguous base calls in electropherograms of ITS and histone H3 sequences, avoiding the need to clone these loci. Chromatograms of the forward and reverse DNA strands were assembled and edited using Sequencher 5.3 (Gene Codes Corp., Ann Arbor, MI, USA). In total, 207 sequences (15 of COI, 54 of 12S, 54 of ATP6-NAD4, 54 of NAD3-NAD5, 15 of histone $\mathrm{H} 3$, and 15 of ITS) were generated and combined with 123 published sequences. Sequences obtained in this study were deposited in EMBL, and accession numbers for all sequences are listed in Table 1.

\section{Morphological observations and characters}

Skeletons of Echinophyllia aspera (UNIMIB BA001), Oxypora lacera (IRD HS3172), and of the specimens identified as Echinophyllia spp. (MNHN IK-2014-250 and MNHN IK-2014-252) were examined at three scales, i.e., macromorphology, micromorphology, and microstructure, for a total of 46 characters (Appendices 1 and 2). These 46 characters ( 20 of macromorphology, 13 of micromorphology, and of 13 microstructure) were identical to those used by Huang et al. (2016; see especially their Ttable 1 and Appendix S2) in their revision of the Lobophylliidae, Budd et al. (2012a; see especially their Appendix S3) in their monograph of the Mussidae, and Huang et al. (2014a) in their revisiontreatise of the Merulinidae. For the remaining lobophylliid species included in the phylogenetic analyses, we used the morphological character states scored by Huang et al. (2016). 
Observations at the macromorphological level were made using a Leica M80 microscope equipped with a Leica IC80HD camera. For analysis at micromorphological and microstructural scales, specimens were observed intact, as broken and etched samples, or as thin sections ( $c a .30 \mu \mathrm{m}$ thick). Transverse broken sections of septa were exposed for $c a .20$ s of etching in $0.1 \%$ formic acid solution, rinsed with distilled water, and air-dried following the procedure described by Stolarski (2003). Once dried, the samples were mounted on stubs and sputter-coated with $\underline{\text { a }}$ conductive platinum film. Thin sections were observed and photographed with a Nikon Eclipse 80i (Tokyo, Japan) transmitted light microscope, whereas intact and broken/etched skeleton samples were observed with a Philips XL 20 (Amsterdam, the Netherlands) scanning electron microscope (SEM). Thin sections and skeletal fragments attached to microscope stubs are housed at the Institute of Paleobiology (ZPAL, Warsaw).

\section{Phylogenetic analyses}

For both molecular and morphological phylogenetic analyses, Orbicella annularis (Ellis \& Solander, 1786) was selected as an outgroup due to its divergence from Lobophylliidae (Huang et al., 2014ạ; 2016). Sequences were aligned with-using MAFFT v. 7.130b (Katoh and Standley, 2013) and the iterative refinement method E-INS-i. The obtained alignments were later run throughprocessed using GBLOCKS v. 0.91b (Castresana, 2000; http://molevol.cmima.csic.es/castresana/Gblocks_server.html) to remove ambiguously aligned regions using the default “less stringent" settings (Data S1). General statistics concerning the obtained sequences and the variability of the six employed markers were calculated with DnaSP v. 5.10 .1 (Librado and Rozas, 2009) (Table 2). Intra- and intergeneric genetic distances were calculated as $p$-distance based on both the combined matrix (Table 3 ) and the individual gene datasets (Table S1) using DnaSP v. 5.10.1, and variance was estimated with $1_{2} 000$ bootstrap replicates.

We performed separated phylogenetic analyses for each DNA locus under three criteria, namely maximum parsimony (MP) using TNT v.1.1 (Goloboff et al., 2008), Bayesian inference (BI) using MrBayes v. 3.2.1 (Ronquist et al., 2012), and maximum likelihood (ML) using Garli v. 2.01 (Zwickl, 2006) (Fig. S1). MP analysis was performed with 10,000 random addition sequence replicates, each employing 100 cycles of sectorial searches, ratcheting, drifting, and tree fusing. Gaps were treated as missing data. Clade stability was determined through $1_{2} 000$ bootstrap replications. Prior to BI and ML, we determined the best partition scheme and nucleotide substitution models using PartitionFinder v. 1.1.1 (Lanfear et al., 2012). We used unlinked branch lengths, the greedy search algorithm for nucleotide sequence, and considered 18 potential partitions: 12S, ITS region, histone H3, and the three codon positions in each of the five protein-coding genes (COI, ATP6, NAD4, NAD3, and NAD5). Partitioning scheme comparison was performed using the corrected Akaike Information Criterion (AIC) and the Bayesian Information Criterion (BIC), testing the influence on the tree topology (Data S2). Four Markov Chain Monte Carlo $(\mathrm{MCMC})$ chains were run for each BI analysis, saving a tree every $1_{2} 000$ generations. The tree searches were stopped when the deviation of split frequencies was less than 0.01 and all parameters reached the stationarity for effective sampling size and unimodal posterior distribution using Tracer v. 1.6 (Rambaut et al., 2014). The first 25\% trees sampled were discarded as burn-in following indications by Tracer. ML topology was obtained under runs repeated three times from random starting trees to check for dependency of the results upon starting conditions. 
Runs were continued until no improvement in $\operatorname{lnLikelihood}>0.01$ was observed for $50_{2} 000$ generations. The robustness of the final ML tree was assessed by performing $1_{2} 000$ nonparametric bootstrap replicates. A $50 \%$ majority rule consensus tree was generated from the $1_{2} 000$ replicates.

To determine if the six individual six-DNA loci had conflicting phylogenetic signals, the incongruence length difference test (ILD) (Farris et al., 1995), implemented in PAUP* v. 4.0b10 (Swofford, 2003) as the partition homogeneity test, was conducted. The analysis was run with heuristic searches and 1,000 bootstrap replicates with ten stepwise random additions, saving one tree at each step, followed by tree bisection reconnection (TBR) swapping. No conflicting signals were detected between the six molecular markers $(P=0.78)$. Therefore, the six DNA regions were concatenated (3965 bp) to infer a fossiltime-calibrated phylogenetic hypothesis of Lobophylliidae. One calibration point was used as constraint for the phylogeny reconstruction. Following Simpson et al. (2011) and the Paleobiology Database (https://paleobiodb.org/), the stratigraphically oldest fossil occurrences of Lobophyllia (includingand Symphyllia Milne Edwards \& Haime, 1848 that is (now accepted as junior synonym of Lobophyllia, following Huang et al. (2016)) wasere used as minimum bound, and the maximum bound was derived from 95\% confidence intervals on this first appearance datum (Strauss and Sadler, 1989), resulting in a time range of 31.3-19 Ma. The phylogenetic relationships and timing of diversification among lobophylliid taxa were estimated

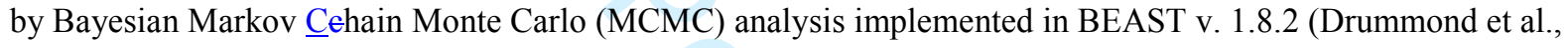
2012). We partitioned the dataset by gene under the evolutionary models presented in Table 2, with unlinked evolutionary models, and an uncorrelated (lognormal) clock model. The analysis was run for 300 million generations, with a sampling frequency of $30_{2} 000$, using four parallel chains. Log files were imported into Tracer v. 1.6 to assess convergence and to ensure adequate ESS values ( $>200$ for each parameter), and then were combined in a single file using LogCombiner v. 1.8.2. We summarised output trees using TreeAnnotator v. 1.8.2 (Drummond et al., 2012), discarding the first $25 \%$ as burn-in, and visualised the maximum clade credibility tree in FigTree v. 1.4.3 (Rambaut, 2012).

Since the new taxon described in this paper could not be distinguished based on a matrix of a distinctive set of morphological characters, the CAOS (Characteristic Attribute Organization System) workbench was used to identify molecular diagnostic character states (Sarkar et al., 2008; http://boli.uvm.edu/caos-workbench/caos.php). Following the method by Jörger and Schrödl (2013), we restricted our search of diagnostic characters to simple pure character attributes $(\mathrm{sPu})$ that exist across all members of a clade but never in any other clade.

For the morphological phylogenetic analysis, we performed a MP analysis on the 46-characters data matrix in TNT (Data S3). We used the same settings used for the MP analyses on the individual gene datasets.- The morphological dataset was composed of 16 binary and 30 multistate characters. Among the latter-ones, 23 traits were treated as ordered, the remaining seven as unordered (Appendix 1). Bremer support values were calculated for each node using TreeRot v.3 (Sorenson and Franzosa, 2007).

To test hypotheses regarding character evolution of the new taxon described hereafter, we performed an ancestral character state reconstruction, mapping each character onto the molecular phylogenetic tree using Mesquite v. 3.02 (Maddison and Maddison, 2015). 


\section{Results}

Molecular data

The six-loci concatenated alignment (COI, 12S, ATP6-NAD4, NAD3-NAD5, histone H3, and ITS) was composed by a total of 3965 characters, including 638 variable sites (SV), of which 143 were singletons, and 495 were parsimony informative (SPI) (Table 2). Alignment lengths varied from a minimum value of $317 \mathrm{bp}$ (histone H3) to a maximum of 844 nucleotides (NAD3-NAD5). The two nuclear markers (histone H3 and ITS) showed the highest proportion of both SV and SPI (higher than 20\%) among the six sequenced loci.

The six single-locus phylogenies were broadly concordant and showed no major evidence of conflicting support and phylogenetic signal among the analysed taxa (Fig. S1). Indeed, most phylogenies recovered the ten known molecular clades (A-J) of Lobophylliidae (Arrigoni et al., 20116b; Huang et al., 2016), with the addition of a novel clade $(\mathrm{K})$. Although the relationships between clades varied between the six molecular markers, each of the analysed species belonged to the same molecular clade in all trees and phylogeny reconstruction criteria.

Interestingly, the thirteen samples preliminarily identified as Echinophyllia spp. within the expected clade E. Instead, they formed a single and separated lineage (clade K) within Lobophylliidae in all analyses, with high node support values (Fig. S1). Hereafter ${ }_{2}$ we formally describe the new taxon Paraechinophyllia gen. nov. corresponding to clade K.

The identification of the sister taxon of Paraechinophyllia gen. nov. was less clear because, for example, it was represented by Moseleya Quelch, 1884 in both ITS and histone H3 trees and by a group composed of several genera such as Mieromussa, Homophyllia, and Australophyllia, Homophyllia, and Micromussa in both COI and NAD3-NAD5 phylogenies. The pairwise comparisons of intergeneric genetic distances confirmed the evolutionary distinctiveness of Paraechinophyllia gen. nov. within Lobophylliidae. Indeed, the intergeneric values between | Paraechinophyllia gen. nov. and the other nine genera within Lobophylliidae varied from $2.35 \pm 0.2 \%$ (Moseleya) to $4.63 \pm 0.29 \%$ (Homophyllia). These distances totally overlapped with the pairwise intergeneric distances for the other genera (Table 3).

The fossiltime-calibrated phylogeny of Lobophylliidae inferred from the six sequenced loci is shown in Fig. 4a. The family iwas subdivided in eleven well-supported molecular clades (A-K) whose posterior probabilities (pp) awere all 1. As already shown by the six single-locus phylogenies, all samples of Paraechinophyllia gen. nov. clustered in a well-supported lineage $(\mathrm{pp}=1)$. Within this clade, the two samples from Mayotte awere basal and sister to the remaining samples from the Gulf of Aden, the Red Sea, and Madagascar. Notably, Paraechinophyllia gen. nov. receives $\mathrm{d}$ high support $(\mathrm{pp}=1)$ as sister to the lineage leading to Echinophyllia and Oxypora. The lineage including these three genera iwas sister to the monophyletic group containing Sclerophyllia and Moseleya ( $\mathrm{pp}=1$ ). Divergence time estimates for some main nodes and genera are listed in Table 4. Based on our results, extant $P$. variabilis sp. nov. originated during the Pliocene (3.2 Ma, 95\% HPD: 1.2-6.4) and diverged from the ancestor of Echinophyllia and Oxypora in the Early Miocene (21.5 Ma, 95\% HPD: 11.6-33.7). The split between Echinophyllia and Oxypora occurred in the Middle Miocene (13.7 Ma, 95\% HPD: 6.3-22.9). The estimated establishment of Paraechinophyllia gen. nov. was comparable to that of Oxypora (3.1 Ma, 95\% HPD: 1.6-5.3) and Homophyllia (4.7 
Ma, 95\% HPD: 1.9-9.7). The youngest genus was Sclerophyllia (0.7 Ma, 95\% HPD: 0.1-2.1) and the oldest one was Lobophyllia (8.4 Ma, 95\% HPD 5.8-13.4).

\section{Morphological data}

The strict consensus tree of the morphological phylogenetic analysis based on 46 characters is shown in presence ofthere are some differences. Seven of the 11 molecular clades (A-D, H-J) were recovered in the morphological tree, of which three clades_,-Micromussa (A), Homophyllia (B), and Lobophyllia (I)), with-had at least moderate support. In contrast with the molecular tree, the representatives of Paraechinophyllia gen. nov. (K), Echinophyllia $(\mathrm{F})$, and Oxypora $(\mathrm{G})$ were grouped together in a monophyletic lineage with high support (MP bootstrap $=92$, Bremer decay index $=4)$. Moreover, Acanthastrea pachysepta (Chevalier, 1975) was sister to the lineage leading to Acanthastrea Milne Edwards \& Haime, 1848 (E) and Paraechinophyllia gen. nov. + Echinophyllia (F) + Oxypora (G), similarly to Huang et al. (2016). Therefore, the latter three genera are morphologically indistinguishable.

The ancestral character state reconstruction revealed that four characters represented unambiguous synapomorphies of the lineage leading to Paraechinophyllia gen. nov., Echinophyllia, and Oxypora: organically united corallites, extensive coenosteum, columellae $\geq 1 / 4$ of calice width, and loss of epitheca (Fig. S2). A total of 43 of the 46 analysed characters were invariable among the three genera. Notably, calice relief wais medium (3-6 $\mathrm{mm})$ in Paraechinophyllia gen. nov. and small $(<3 \mathrm{~mm})$ in Echinophyllia and Oxypora. Trabecular and compact (1-

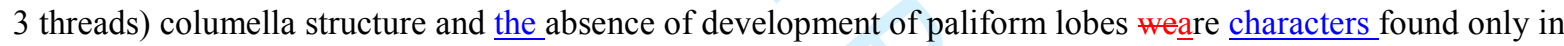
Oxypora. Conversely, Paraechinophyllia gen. nov. and Echinophyllia showest trabecular and spongy (> 3 threads) columella structure and weak or moderate development of paliform lobes.

The examined specimens of Paraechinophyllia gen. nov. consistently showed microtextural and microstructural features that previously were recognised in other lobophylliids (Huang et al., 2016); see Figs-Figs. 57. These included distinct microtuberculate texture on surfaces of skeletal structures. Tips of these microtubercules corresponded to slender bundles of fibres that form thickening deposits (TD's). Consistent with symbiotic (zooxanthellate) status of Paraechinophyllia gen. nov., its thickening deposits showed regular growth banding (Figs Figs. 6j, 7h; see Frankowiak et al., 2016). The organiszation of Rapid Accretion Deposits (RAD's) in Paraechinophyllia gen. nov. showed the same overall pattern and variable arrangement as occurs in the closely related taxa Echinophyllia (Fig. 5j-m, see also Fig. S3) and Oxypora (Fig. 5g-i): RAD's of sectioned lower order septa of more robust morphotypes form clusters with projections extending toward the septal faces (these structures typically represent various stages of septal tooth development). In contrast, RAD's in higher order septa or septa of less robust morphotypes formed straight or wavy mid-septal zone (Figs-Figs. 5e, 6b).

\section{Taxonomic account}

Scleractinia Bourne, 1900

Lobophylliidae Dai and Horng, 2009

Paraechinophyllia Arrigoni, Benzoni \& Stolarski gen. nov. 
Figs. 1-3, 5I-N, 7

Type species. Paraechinophyllia variabilis Arrigoni, Benzoni \& Stolarski sp. nov.

Etymology. Paraechinophyllia alludes to its morphological similarities with Echinophyllia, but it is distinguished from the latter based on genetics.

Included species. Paraechinophyllia variabilis Arrigoni, Benzoni \& Stolarski sp. nov.

Diagnosis (character different from both Echinophyllia and Oxypora in italics). Colonial and laminar. Budding intracalicular; peripheral budding may be present. Corallites may be polymorphic; organically united. Monticules absent. Coenosteum spinose; extensive amount of coenosteum ( $\geq$ corallite diameter). Calice width medium to large ( $\geq 4 \mathrm{~mm})$, with medium relief $(3 \mathrm{~mm})$. Costosepta mostly confluent. Septa in $\leq 3$ cycles $(\leq 16$ septa). Free septa irregular. Septa spaced $\leq 4$ septa per $5 \mathrm{~mm}$. Costosepta unequal in relative thickness. Columellae trabecular and spongy ( $>3$ threads), $\geq 1 / 4$ of calice width, and discontinuous amongst adjacent corallites with lamellar linkage. Columellae centres clustered. Paliform lobes weakly or moderately developed. Development of septal lobes absent. Epitheca absent. Endotheca low-moderate (tabular). Tooth base at midcalice elliptical-parallel. Tooth tip outline irregular, forming multiaxial bulb. Tooth height medium $(0.3-0.6 \mathrm{~mm})$. Tooth spacing medium $(0.3-1.0 \mathrm{~mm})$, with $\leq 6$ teeth per septum. Tooth size equal between wall and septum. Granules scattered on septal face; weak (rounded). Interarea smooth. Walls formed by dominant paratheca and partial septotheca. Thickening deposits with extensive stereome. Costa centre clusters weak; $>0.6 \mathrm{~mm}$ between clusters; medial lines strong. Septum centre clusters weak; $0.3-0.5 \mathrm{~mm}$ between clusters; medial lines weak.

Genetics. This genus is a monophyletic clade within Lobophylliidae and is sister to the lineage leading to Echinophyllia and Oxypora based on our multi-locus phylogeny reconstruction (COI, 12S, ATP6-NAD4, NAD3NAD5, histone H3, and ITS) (Fig. 4a). The split between these two lineages occurred in the Early Miocene (21.5 Ma, 95\% HPD: 11.6-33.7). A total of 21 diagnostic nucleotide characters (with position in alignment): COI: T (587); 12S: G (492), C (678); ATP6-NAD4: C (149), C (211), C (394), T (543); NAD3-NAD5: C (57), T (150), A (183), C (235); histone H3: G (7); ITS: G (108), G (109), G (114), G (140), C (232), C (245), C (261), C (282), G (482), G (553).

Distribution. Red Sea (Saudi Arabia), northern and western Gulf of Aden (Yemen), and southern and western Indian Ocean (Madagascar and Mayotte Island).

Remarks. This genus is monotypic, including only Paraechinophyllia variabilis sp. nov. It is morphologically indistinguishable from Echinophyllia and Oxypora as shown in the morphological phylogeny (Fig. 4b) and the establishment of this genus is based on genetic data. The fossiltime-calibrated molecular phylogeny proposed in Fig. 4a demonstrated that this genus is a distinct and monophyleyic clade of Lobophylliidae that is deeply divergent from the lineage leading to Echinophyllia and Oxypora. Each of the six single-locus phylogenies confirmed that this genus is not related to any other lobophylliid genus. It has been recorded from the Red Sea, the northern and western Gulf of Aden, and southern and western Indian Ocean but was not collected in Maldives and in several other localities of the Pacific Ocean (e.g. Papua New Guinea, New Caledonia, Australia) where a similar sampling effort on lobophylliid diversity has been carried out. Unfortunately, no other localities of the southern and 
western Indian Ocean have been surveyed in this study and, therefore, the possible presence of this species in this region cannot be excluded.

\section{Paraechinophyllia variabilis Arrigoni, Benzoni \& Stolarski sp. nov.}

Figs. 1-3, 5I-N, 7

Etymology. Variabilis means "variable" in Latin and refers to the notable morphological variability of the species.

Type material. Holotype: MNHN-IK-2014-250, Tara Oceans Expedition, Mayotte Island (1241.193'S; 44 59.039'E), 14/06/2010, collector Benzoni F, collection code UNIMIB MY236. Paratypes: MNHN-IK-2014-251, Tara Oceans Expedition, Mayotte Island (1240.429'S; 45³.690'E), 31/05/2010, collector Benzoni F, collection code UNIMIB MY050; MNHN-IK-2014-247, Al Mukallah, Yemen (14² 29.967'N; 49²10,328'E), 19/03/2007, collector Benzoni F, collection code UNIMIB MU132; MNHN-IK-2014-252, Al Mukallah, Yemen, (14³0.793'N; 49¹0,339'E), 20/03/2007, collector Benzoni F, collection code UNIMIB MU165.

Other material examined. Saudi Arabia, Red Sea, KAUST Biodiversity cruise, collector Benzoni F: KAUST SA0021, Al Lith, Shi'b Ammar (19³4.242'N; 4000.527'E), 03/03/2013; KAUST SA0794, Jaz'air Silah

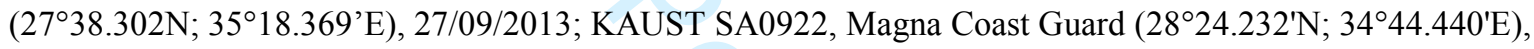
29/09/2013; KAUST SA0944, Magna Coast Guard (28²4.232'N; 34²44.440'E), 29/09/2013,; KAUST SA1023, Gulf of Aqaba, Magna Coast Guard (28²4.232'N; 3444.440'E), 30/09/2013; Madagascar, MAD cruise, collector Benzoni F: IRD MD239, Nosy Kalakajoro (13²19.028'S; 488.832'E), 28/10/2016; IRD MD240, Nosy Kalakajoro, (13²19.028'S; 488.832'E), 28/10/2016; MD241, Nosy Kalakajoro, (13¹9.028'S; 488.832'E), 28/10/2016; MD265, Nosy Sakatia (13055.749'S; 47²5.346'E), 30/10/2016.

Description. The holotype (MNHN-IK-2014-250) corallum is irregularly dome-shaped and circular in outline at the base with the largest diameter measuring $12 \mathrm{~cm}$ (Figs-Figs. 1a, 3a). It was attached at the substrate at the centre of the colony and has free margins. Corallites are crowded and irregularly oriented at the centre of the specimen and tend to space out towards the margins. Corallite shape and size are variable, the largest has an elliptical shape and measures $18 \mathrm{~mm}$ in largest diameter and the smallest $10 \mathrm{~mm}$ (Fig 2a). Calices have medium relief. Columellae are trabecular and spongy seateding deep in the fossa (Fig 2a) where moderately developed paliform lobes are found. Costosepta are equal, going from 12 to 24 in number. Septal teeth have irregular tip outline forming multiaxial bulbs visible to the naked eye. Paratype MNHN-IK-2014-251 is a dome-shape corallum similar in shape to the holotype but larger than it ${ }_{2}$ measuring $16 \mathrm{~cm}$ in largest diameter (Figs-Figs. 1b, 3b). Its corallites are more regularly arranged and exsert (Figs-Figs. 2b, 3b). The specimen closely resembles the holotype in terms of size and shape of the corallites; and all the other aforementioned features. However, paratype MNHN-IK2014-251 has particularly thick and high septal teeth, the most developed in the type series described here, which give the costosepta an even rougher appearance (Fig. 2b). Paratype, MNHN-IK-2014-252 (Fig. 3c) is the peripheral fragment of a larger colony. It measures $16 \times 8 \mathrm{~cm}$ and shows several visible differences with the two previously examined specimens in the type series. In particular, although the corallite size in this specimen remains within the medium to large ( $\geq 4 \mathrm{~mm}$ ) range, it is smaller on average, with most corallites barely reaching $10 \mathrm{~mm}$ in diameter 
(Fig. 2e). Moreover, radial elements are overall thinner and more distanced, with septal teeth similarly reduced in thickness when compared to the holotype. Because corallites are more scattered on the colony surface and radial elements are overall thinner, alveoli are easily visible in this paratype. Similarly to the previous specimen, paratype MNHN-IK-2014-247 (Figs-Figs. 1e, 3d) is a peripheral portion of a predominantly foliose colony. It measures $11 \mathrm{x}$ $7.5 \mathrm{~cm}$ and it most resembles MNHN-IK-2014-252 among the examined specimens having a similar corallite size, smaller than that of the holotype and paratype MNHN-IK-2014-251, and costosepta and septal teeth morphology, especially in terms of their reduced thickness (Fig. 2e).

Other specimens examined in this study and included in the genetic analyses fall within the corallum and corallite morphological variability range encompassed by the type specimens described above (Figs-Figs. 1c, g-h, 2c-d, g-h) and mostly resembling either Echinophyllia- aspera or E. orpheensis. Notably, some specimens may show particularly bulbous ornamentation on the primary septa typical of the recently described species E. bulbosa (Arrigoni et al. 2016c) (Figs-Figs. 1f, 2f).

Genetics. Same as for the genus.

Distribution. Same as for the genus.

Remarks. This species is morphologically similar to both Echinophyllia aspera and E. orpheensis but the genetic data revealed its deep divergence from these two Echinophyllia species. IMøre in particular, while the holotype and paratype MNHN-IK-2014-251 show strong resemblance with Echinophyllia orpheensis, paratypes MNHN-IK-2014-247 and MNHN-IK-2014-252 were initially identified as E. aspera. This species occurs in sympatry with E. aspera and E. orpheensis, sharing the same reef habitat where specimens of these three species were collected for this study.

\section{Echinophyllia Klunzinger, 1879}

Type species. Echinophyllia aspera (Ellis \& Solander, 1786)

Revised diagnosis. Colonial and laminar. Budding intracalicular; peripheral budding may be present. Corallites may be polymorphic; organically united. Monticules absent. Coenosteum spinose; extensive amount ( $\geq$ corallite diameter). Calice width medium to large $(\geq 4 \mathrm{~mm})$, with small relief $(\leq 3 \mathrm{~mm})$. Costosepta mostly confluent. Septa in $\leq 3$ cycles $(\leq 36$ septa). Free septa irregular. Septa spaced $\leq 11$ septa per 5 mm. Costosepta unequal in relative thickness. Columellae trabecular and spongy ( $>3$ threads), $\geq 1 / 4$ of calice width, and discontinuous amongst adjacent corallites with lamellar linkage. Columellae centres clustered. Paliform lobes weakly or moderately developed. Septal lobes absent. Epitheca absent. Endotheca low-moderate (tabular). Tooth base at midcalice elliptical-parallel. Tooth tip outline irregular, forming multiaxial bulb. Tooth height medium (0.3$0.6 \mathrm{~mm})$. Tooth spacing medium $(0.3-1.0 \mathrm{~mm})$, with $\leq 6$ teeth per septum. Tooth size equal between wall and septum. Granules scattered on septal face; weak (rounded). Interarea smooth. Walls formed by dominant paratheca and partial septotheca. Thickening deposits extensively developed. Costa centre clusters weak; $>0.6 \mathrm{~mm}$ between clusters; medial lines strong. Septum centre clusters weak; 0.3-0.5 mm between clusters; medial lines weak.

Genetics. This genus is sister to Oxypora based on our multi-locus phylogeny reconstruction (COI, 12S, ATP6-NAD4, NAD3-NAD5, histone H3, and ITS) (Fig. 4a). The estimated split between the two genera occurred in 


\section{Oxypora Saville-Kent, 1871}

\section{Type species. Oxypora lacera (Verrill, 1864)}

Revised diagnosis (characters different from both Paraechinophyllia and Echinophyllia in italics). Colonial and laminar. Budding intracalicular; peripheral budding may be present. Corallites may be polymorphic; organically united. Monticules absent. Coenosteum spinose; extensive amount of coenosteum ( $\geq$ corallite diameter). Calice width medium (4-15 mm), with small relief $(\leq 3 \mathrm{~mm})$. Costosepta mostly confluent. Septa in $\leq 3$ cycles $(\leq 24$ septa). Free septa irregular. Septa spaced $\leq 6$ septa per $5 \mathrm{~mm}$. Costosepta unequal in relative thickness. Columellae trabecular and compact (1-3 threads), $\geq 1 / 4$ of calice width, and discontinuous amongst adjacent corallites with lamellar linkage. Columellae centres clustered. Paliform lobes absent. Septal lobes absent. Epitheca absent. Endotheca low-moderate (tabular). Tooth base at midcalice elliptical-parallel. Tooth tip outline irregular, forming multiaxial bulb. Tooth height medium $(0.3-0.6 \mathrm{~mm})$. Tooth spacing medium $(0.3-1.0 \mathrm{~mm})$, with $\leq 6$ teeth per septum. Tooth size equal between wall and septum. Granules scattered on septal face; weak (rounded). Interarea smooth. Walls formed by dominant paratheca and partial septotheca. Thickening deposits extensively developed. Costa centre clusters weak; $>0.6 \mathrm{~mm}$ between clusters; medial lines strong. Septum centre clusters weak; $\geq 0.6 \mathrm{~mm}$ between clusters; medial lines weak.

Genetics. This genus is sister to Echinophyllia based on our multi-locus phylogeny reconstruction (COI, 12S, ATP6-NAD4, NAD3-NAD5, histone H3, and ITS) (Fig. 4a). A total of 44 diagnostic nucleotide characters (with position in alignment): ATP6-NAD4: G (364), G (435), G (501), C (783); NAD3-NAD5: A (209); histone H3: A (10), C (22), T (40), C (55), C (58), G (88), T (91), T (94), T (109), C (115), T (118), C (124), C (136), G (142), G (145), C (163), C (184), T (187), C (202), T (211), C (214), G (217), C (223), A (230), G (232), T (238), T (247), T (256), C (259), C (269), A (277), C (280), T (287), C (295), G (307), C (310); ITS: T (196), G (479), C (629). 
Included species. Oxypora lacera (Verrill, 1864); Oxypora convoluta Veron, 2000; Oxypora crassispinosa Nemenzo, 1979; Oxypora echinata (Saville-Kent, 1871)_comb. nov.; Oxypora egyptensis Veron, 2000.

Taxonomic remarks. Given the deep molecular divergences between Echinophyllia $(\mathrm{F})$ and Oxypora $(\mathrm{G})$ and with the aim to maintain the two as monophyletic entities genera monophyletic, Echinophyllia echinata (Saville-Kent, 1871) is transferred to Oxypora based on genetics. Therefore, the new combination Oxypora echinata is here established for the first time.

\section{Discussion}

As a result of the morphological and molecular analyses presented in this study, Paraechinophyllia variabilis was described as a new cryptic genus and species ascribed to the-Lobophylliidae. The genus is genetically distinct from the other lobophylliids based on six molecular loci and diverged from the most closely related Echinophyllia and Oxypora approximately $21.5 \mathrm{Ma}$. Nevertheless, the presented-morphological phylogeny reconstruction did not separate the new genus from Echinophyllia and Oxypora and onlya one (medium calice relief, 3-6 mm) out of 46 morphological characters distinguished Paraechinophyllia from the latter two genera. Colony growth form and corallite features of $P$. variabilis closely resemble those of E. aspera and E. orpheensis and, moreover, the species is characterised by a notable intraspecific morphological variation.

Central tenants-topics of cladistics are the concepts of monophyly and synapomorphy. A monophyletic taxon originates with speciation and it is defined as one that includes the ancestor and all_(-and only); its descendants (Wiley, 1981). Synapomorphy is the empirical trait used to discover and describe a monophyletic taxon (Hennig, 1957). The establishment of $P$. variabilis based on genetic data strictly followed the Hennigian principle of monophyly (Hennig 1950, 1966). The analysed samples of the new taxon consistently grouped in a well-supported monophyletic lineage in the phylogenetic tree of each individual gene; phylogenetic tree and-retaining this taxon in Echinophyllia would have created a paraphyletic group given the non-sister relationship between Paraechinopyllia and Echinophyllia (Fig. S1). By analysing six independent DNA loci, CAOS discovered 21 diagnostic nucleotide characters for the new taxon. Although the detection of homologies and apomorphic conditions of a nucleotide is demanding because of the high chance of convergent multiple transformations generating homoplasy, we confidently assumed these characters as synapomorphies for Paraechinophyllia based on the following considerations: the CAOS search was restricted to sPu that exist across all members of Paraechinophyllia but never in any other lobophylliid clade; the high taxon coverage of the family by the inclusion into the phylogenetic analyses of all extant genera and of 46 out of the 54 (85\%) valid species ascribed to Lobophylliidae; and the deep divergence time between Paraechinopyllia and the lineage leading to Echinophyllia and Oxypora increased the chance that the discovered sPu referred to unique mutations accumulated due to selectionthe absence of gene exchange.

\section{What is a cryptic taxon?}

Speciation is not always accompanied by morphological change and the identification of cryptic taxa has challenged taxonomists and naturalists since the $18^{\text {th }}$ century (Winker, 2005). Hidden diversity implicates mechanisms of morphologically static cladogenesis and suggests the occurrence of selection on ecological, 
behavioural, and/or reproductive characters which do not correspond to phenotypic differences (Bickford et al., 2007; Fišer et al., 2018). Stabilising selection on morphology is often hypothesised in several models of cryptic speciation, especially in the presence of extreme environmental conditions (Schönrogge et al., 2002). Some studies highlighted that patterns of cryptic genetic divergence are strongly associated with ecological niche differentiation (Rissler and Apodaca, 2007). In addition, prezygotic and/or postzygotic barriers play an important role in speciation mechanisms despite morphological stability (Knowlton, 1993; Palumbi, 1994). In our case, P. variabilis occurs in sympatry with E. aspera and E. oprheensis, even sharing also the same reef habitat. Moreover, we did not find any depth partitioning or light and water condition preferences. Therefore, it seems that these three species have similar ecological characteristics. Sexual The sexual system and reproductiveen mode are known for three Echinophyllia species (E. aspera, E. orpheensis, and E. glabra) and two Oxypora species (O. lacera and O. crassispinosa) (Baird et al., 2009; Bouwmeester et al., 2015). All these species are gonochoric broadcast spawners. Since a difference in spawning timing may represent an important prezygotic barrier, further studies on spawning behaviour and reproductive mode of $P$. variabilis should be undertaken to investigate in detail the role of reproductive barriers among these taxa.

Some researchers advocated that cryptic species should beare often included in the category of pseudocryptic species once the establishment of diagnosable morphological and non-morphological traits for their identification (Sáez and Lozano, 2005; Fišer et al., 2018). Indeed, in several cases further examinations of morphology, physiology, and behaviour resolved and identified pseudo-cryptic species (Knowlton, 1993; Sáez et al., 2003) and suggested the need of a critical investigation of the entire morphological space to test the real cryptic nature of a taxon. In this study, following the most updated works on coral cladistics (Budd and Stolarski, 2009; Budd et al., 2012a; Huang et al., 2016), a rigorous phylogenetic analysis of 46 morphological characters has been coupled with genetics to a taxon-rich dataset of Lobophylliidae. Nevertheless, we acknowledge that the analysed morphological traits refer exclusively to the coral skeleton and we do not exclude that key differences could be found by investigating other features, such as those related to the coral polyps or to embryogenesis. Histological characters remain under-explored in scleractinian phylogenetics despiteeven though they are routinely used in other cnidarian groups (Fautin, 2009). Recent works demonstrated that soft-tissue traits are taxonomically valid and increased phylogenetic resolution. although some caveats should be made (Martinez-Baraldés et al., 2014; Cordie et al., 2016). Embryogenetic morphological characters distinguished "complex" from "robust" corals, suggesting that patterns of early development and gastrulation are phylogenetically informative rather than being correlated with habitat or reproductiveen mode (Okubo et al., 2013; Okubo, 2016). Interestingly, Okubo (2016) stated that "gastrulation mode such as delamination, invagination, ingression etc. could be used for grouping at the family or genus level, because the gastrulation mode is different at least among genera". Other non-morphological lines of evidence have been used to differentiate found to be different in-some cryptic corals. For example, differences in spawning times and reproduction strategies were found in hidden lineages of Acropora (Rosser, 2015) and Pocillopora (Pinzón et al., 2013; Schmidt-Roach et al., 2013a). In addition, partitioning of Symbiodinium associated to distinct cryptic species were was detected in Seriatopora (Bongaerts et al., 2010; Warner et al., 2015) and Pocillopora (Schmidt-Roach et al., 2013a), thus suggesting the possible importance of symbionts in the host cryptic 
diversity. In all these cases $_{2}$ it may be hypothesised that different ecological niches are associated with cryptic species (Rissler and Apodaca, 2007). In other instances, the lack of any known phenotypic and ecological differences suggests that cryptic species could occupy highly overlapping ecological niches, suggesting that their long-term coexistence could be unstable and that neutral mechanisms and ecological drift might be especially important in their community dynamics (McPeek and Gomulkiewicz, 2005).

With the aim to understand and discover cryptic species, researchers need to look for the conditions in which sibling taxa will thrive, pursuing their causes whilst decrypting their nature. We need to apply systematic and quantitative comparisons across taxa, biogeographic areas, and habitats. Surveying poorly-studied groups and regions and understanding the biology of a taxon are two fundamental aspects to enhance the chances for discovering cryptic species and determining their origin. Under this premise, coral reefs and hard corals are promising candidates to explore the occurrence of sibling taxa (Knowlton, 1993). Coral reefs are heterogeneous environments, characterised by a plethora of different habitats, environmental parameters, and specialised interspecific interactions, enhancing the occurrence of severe selection and speciation (Bickford et al., 2007). Hard corals are relatively simple marine invertebrates (Veron, 2000), with few taxonomically informative characters, and thus with a high potential of hidden speciation (Knowlton, 1993). Therefore, it is not surprising that during the last years an increasing number of cryptic species has been unravelledrevealed using various genetic approaches, suggesting that cryptic speciation occurs in several coral genera (Kitahara et al., 2016).

Origin of Paraechinophyllia

Several recent molecular studies discovered multiple instances of evolutionary differentiation between the Indian and Pacific coral fauna, including unique Indian lineages and unexpected evolutionary breaks between Indian and Pacific coral populations (Flot et al., 2011; Stefani et al., 2011; Arrigoni et al., 2012, 2016a, 2016b, 2016c; Benzoni et al., 2012a; Arrigoniet al., 2012, 2016a, 2016b, 2016e; Huang et al., 2014b; Kitano et al., 2014; Richards et al., 2016; Gélin et al., 2017b). The description of Paraechinophyllia increases the number of coral genera endemic to the northern and/or western Indian Ocean, including Anomastraea, Coscinaraea, Craterastrea, Ctenella, Gyrosmilia, Horastrea, and Sclerophyllia (Veron, 2000; Benzoni et al., 2012a; Arrigoni et al., 2015). This result confirms the evolutionary distinctiveness of corals living in this region (Obura 2012) and strengthens the hypothesis of a second biodiversity hotspot for scleractinian corals besidesafter the Coral Triangle and the adjacent South China

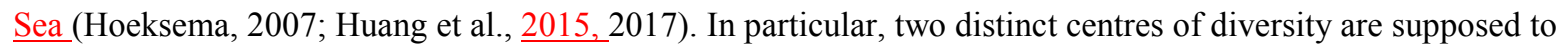
occur in the Indian Ocean, the northern Mozambique Channel and the Red Sea (Obura, 2012; Veron et al., 2015). Notably, Paraechinophyllia occurs in both the northern Mozambique Channel and the Red Sea. Notably, the timetree showed that Mayotte samples of $P$. variabilis are basal while the Red Sea representatives are the most derived and recent (Fig. 4a). This result suggests an origin of Paraechinophyllia in the northern Mozambique Channel, followed by a recent dispersal towards the northern Indian Ocean.

It is now accepted that the distribution of extant scleractinian corals does not necessarily coincide with breaks in contemporary environmental conditions and habitats, but it is conversely influenced by geological features, such as tectonic plates and mantle plume tracks (Keith et al., 2013; Leprieur et al., 2016). The fossiltime- 
calibrated phylogenetic tree indicated an Early Miocene timing ( 21.5 Ma) for the beginning of the radiation of extant lineages of Paraechninophyllia, Echinophyllia, and Oxypora (Fig. 4a). Evidence from distribution patterns, phylogenetic studies, paleontology, and geology suggest that multiple centres of origin have occurred in the Indian Ocean from the Paleogene onwards as results of geological events (Obura, 2016). Important tectonic changes in what is now the northern and central Indian Ocean occurred in the Eocene, resulting in a narrowing of the Tethys Sea (Schettino and Turco, 2011). Europe became isolated from the Indian Ocean and the circumtropical Tethys Sea started a process of fragmentation that implicated the isolation of the western and northern Indian Ocean from the eastern Indian Ocean and the Central Indo-Pacific (Meulenkamp and Sissingh, 2003). Following the collision of India with Asia, the remnants of the Tethys Sea closed during the Miocene (25-15 Ma) and the emergent Mascarene Ridge islands constituted an intermittent north-south barrier that would have further isolated the western Indian Ocean (Obura, 2016). Therefore, the origin of the lineage leading to P. variabilis may have been driven by geological processes related to the fragmentation of the Tethys Sea and the transition of the biodiversity hotspot from the West Tethys Sea to the East Africa/Arabian plate (Obura, 2016).

The six-loci timetree-chronogram indicates genera (Fig. 4a) and this is concordant with fossil occurrences of the majority of these taxa (see the Paleobiology Database, https://paleobiodb.org/ Fossil). Evidence suggestes d that tectonic events in the Late Oligocene and early Miocene promoted a general increase of shallow-water areas and the creation and diversification of a mosaic of distinct habitats (Wilson and Rosen, 1998; Zanchos et al., 2001; Crame and Rosen, 2002). As outcomeBecause of these tectonic dynamics and habitat changes, this period is characterised by an exceptional documented diversification of zooxanthellate corals and reef-associateds organisms (Bellwood et al., 2004; Cowman et al., 2011). Multiple and independent instances of increased rates of diversification in the Oligocene and Miocene have been described for reef fish (Alfaro et al., 2007; Bellwood et al., 2004; Cowman et al., 2011; Litsios et al., 2014), octocorals (Herrera et al., 2012; Dueñas et al., 2016), gastropods (Williams and Duda, 2008), crustaceans (Shank et al., 1999; Klaus et al., 2010), and molluscs (Strugnell et al., 2008).

Morphological considerations on Paraechinophyllia variabilis

Due to its cryptic nature and remarkable similarity with Echinophyllia and Oxypora, Paraechinophyllia has been overlooked so far. Considering the sister relationship between Paraechinophyllia and the molecular lineage leading to former two genera (Fig. 4a), it is likely that the morphological similarity is determined by the conservation of morphological traits from their common ancestor over a very long period. It seems that these three genera will occupy a similar morphospace (McGhee, 2006) and aA detailed re-examination of their fossil record may elucidate the possible occurrence of morphological stasis (Eldredge et al., 2005). Notably, a recent study showed that extant Acropora species conserved morphological microstructures and biomineralisation patterns identical to those of fossil Acropora from the Eocene, Oligocene, and Miocene, spanning a period of $48 \mathrm{Ma}$ (Stolarski et al., 2016). Nevertheless, extant Acropora species are highly diversified and morphological different from extinct onesthe fossil species (Wallace, 1999; Wallace and Rosen, 2006; Santodomingo et al., 2015). In 
contrast to our study case, Acropora species occupy distinct regions of morphospace (McGhee, 2006) and represent an example of morphology conservation from the ancestor.

Another interesting aspect is that $P$. variabilis is macromorphologically indistinguishable from $E$. aspera and its closely related species $E$. orpheensis, whereas it can-be easily be toldtell apartdistinguished from all the other Echinophyllia and Oxypora species. Although E. aspera and E. orpheensis likely represent different morphsa of a single species (Arrigoni et al., 2016a; see also discussion below), they are clearly separated from P. variabilis based on genetics. It seems therefore that the new taxon and the lineage including E. aspera and E. orpheensis have independently evolved similar macromorphologies. $\underline{\text { A similar example has recently been revealed among mushroom }}$ corals (Fungiidae), in which the new genus Sinuorata was discerned as a result of molecular analyses (Oku et al., 2017)A similar case has been recently described in mushroom corals. Oku et al. (2017) described Sinuorata as a result of molecular analyses. Thise monotypic genus is morphologically difficult to separate from free-living Cycloseris species (sensu Benzoni et al. 2012b) but it represents a distinct molecular lineage.

The large intraspecific morphological variability of $P$. variabilis may be due to either phenotypic plasticity, geographic variation, or morphological polymorphism. Different morphologies were collected in similar habitats and environmental conditions, suggesting that phenotypic plasticity is not the-solely responsible for the observed morphological variation. Genetic segregation was detected among three of the four localities where we found $P$. variabilis:- Mayotte Island, the Gulf of Aden, and the Red Sea. Đespite-Although the sample size is admittedly small for each locality, colonies from Mayotte Island and Madagascar were exclusively E. orpheensis-like (Figs-Figs. 1ab) whereas the ones from the Gulf Aden were E. aspera-like (Fig. 1e). This pattern may partly suggest the occurrence of geographic variation among the analysed colonies, but morphologies of the Red Sea population exhibited both morphs and were intermediate between those from Mayotte and the Gulf Aden (Figs-Figs. 1c-d, f-h). These considerations suggest that genetic factors, perhaps related for example-to calcification or development, are at least partially responsible of the encountered pattern of morphological polymorphism.

Paraechinophyllia variabilis exhibits a remarkable morphological variation at the colony and corallite level. Analogous cases of extreme intraspecific morphological variation were previously discussed in other genera of corals, including for example ${ }_{2}$ Cycloseris (Gittenberger and Hoeksema, 2006), Stylophora (Veron and Pichon, 1976; Flot et al., 2011), Pocillopora (Veron and Pichon, 1976; Pinzón et al., 2013), Montastraea (Budd et al., 2012b), and Favia (Carlon and Budd, 2002). On the one hand, colonies of $P$. variabilis can be encrusting, massive, and seldom foliaceous (Fig. 1). Nevertheless, colony shape and growth form can be plastic features affected by homoplasy and influenced by habitat, and therefore they are now recognised as uninformative characters in defining coral species (Flot et al., 2011; Hoeksema and Waheed, 20141; Huang et al., 2014b; Arrigoni et al., 2016a; Addamo et al., 2016). On the other hand, corallite dimension and protrusion eonsiderable-varied considerably among the analysed specimens: some colonies showed large and protruding corallites (Figs-Figs. 2A-B and 3A-B) similar to E. orpheensis, while other specimens (Figs-Figs. 2G-H and 3C-D) displayed smaller and less exsert corallites like E. aspera. The variability of these two corallite features in E. aspera and E. orpheensis was described and illustrated by Arrigoni et al. (2016c). The two morphological characters were greatly variable at both inter- and intracolony levels and a continuum morphological range of morphological variation was detected between the two species. Moreover, 
E. aspera and E. orpheensis were genetically indistinguishable and the authors suggested that the two species should be considered as a single entity. Therefore, the large intraspecific morphological variation of $P$. variabilis is not surprising per se and it is indeed similar to what was already found in E. aspera and E. orpheensis (Arrigoni et al., 2016c).

Paraechinophyllia variabilis shows the same overall microstructural pattern as in Echinophyllia and Oxypora: RAD's in lower order septa or in more robust morphotypes are arranged perpendicularly to the septal plane, whereas RAD's in higher order septa or septa of less robust morphotypes form ef $\underline{a}$ straight or wavy midseptal zone (Figs. 5-7). The surface of skeletal elements (especially newly growing septa) shows microtuberculate texture that corresponds to slender bundles of fibres that form thickening deposits (TD's). The latter skeletal character seems to be distinct to lobophylliids, similarly to other family-specific characters, for example, as e.g., shingled TD's are-typical of acroporiids, or irregular meshwork of fiber bundles is-typical of micrabaciids (Janiszewska et al. 2011; Stolarski et al. 2011, 2016;). A lack of microstructural characters that would separate Paraechinophyllia from closely related taxa suggests that the fine-scale biomineralisation activity was not affected by the processes that lead to molecular divergence.

\section{Conclusions}

Some species are cryptic or hidden to-from human perception largely due to the lack of conspicuous differences in outward appearance. The uptake of DNA sequencing techniques has resulted in the discovery of novel cryptic taxa that constitute an important fraction of contemporary biodiversity (Mora et al., 2011; Scheffers et al., 2012). However, the practice of describinge novel taxa based on DNA sequence information is still poorly adopted and various criticisms are invokedhave arisen (DeSalle et al., 2005; Vogler and Monaghan, 2007). We strongly believe that the absence of diagnostic morphological characters should not preclude the formal description of a new taxon when molecular data are robust and summarised in reproducible protocols (Fišer et al., 2018), such as in the case of $\underline{P}$. variabilis. This is noteworthy in a time of-global biodiversity crisis andand frequenthigh number of extinction episodes (Barnosky et al., 2011). Moreover, in several cases further and detailed morphological and ecological analyses with the inclusion of additional or novel characters have recovered diagnostic traits for the identification of cryptic taxa (Sáez and Lozano, 2005). Finally, the establishmenting of standard protocols to retrieve molecular diagnostic nucleotides from DNA sequences, such as the_employed CAOS software employed here (Sarkar et al., 2008; Jörger and Schrödl, 2014), have introduced reliable and consistent procedures for species descriptions (Cook et al., 2010; Jörger and Schrödl, 2013).

\section{Acknowledgements}

This project was supported by funding from KAUST (award \# URF/1/1389-01-01, FCC/1/1973-07, and baseline research funds to ML Berumen). This research was undertaken in accordance with the policies and procedures of the King Abdullah University of Science and Technology (KAUST). Permissions relevant for KAUST to undertake the research have been obtained from the applicable governmental agencies in the Kingdom of Saudi Arabia. We wish to thank the captain and crew of the MV Dream-_Master, the KAUST Coastal and Marine 
Resources Core Lab, and A Gusti (KAUST) for fieldwork logistics in the Red Sea. We thank JM Reimer (University of Ryukyus), M Oliverio (Sapienza University), and D Maggioni (UNIMIB) for the fruitful discussions about cryptic taxa and CAOS. We are also grateful to E Dutrieux, CH Chaineau (Total SA), R Hirst, M Abdul Aziz (YLNG), and M Pichon (MTQ) for allowing and supporting research in Yemen. We are grateful to E Karsenti $(E M B L)$, and-E Bougois (Tara Expeditions), and-the OCEANS Consortium for allowing sampling during the Tara Oceans expedition in Mayotte. We thank the commitment of the following people and additional sponsors who made this singular expedition possible: CNRS, EMBL, Genoscope/CEA, VIB, Stazione Zoologica Anton Dohrn, UNIMIB, ANR (projects POSEIDON/ANR-09-BLAN-0348, BIOMARKS/ANR-08-BDVA-003, PROMETHEUS/ANR-09-GENM-031, and TARA-GIRUS/ANR-09-PCS-GENM-218), EU FP7 (MicroB3/No.287589), FWO, BIO5, Biosphere 2, agnès b., the Veolia Environment Foundation, Region Bretagne, World Courier, Illumina, Cap L'Orient, the EDF Foundation EDF Diversiterre, FRB, the Prince Albert II de Monaco Foundation, Etienne Bourgois, the Tara schooner, and its captain and crew. Tara Oceans would not exist without continuous support from 23 institutes (http://oceans.taraexpeditions.org). This article is contribution number XX $\underline{73}$ of the Tara Oceans Expedition 2009-2012. New Caledonia data and specimens were obtained during the IRD CORALCAL4 (http://dx.doi.org/10.17600/12100060), BIBELOT (http://dx.doi.org/10.17600/14003700), and CORALCAL5 (http://dx.doi.org/10.17600/15004300) expeditions on the RV Alis. Material from Madagascar was collected during the MAD (http://dx.doi.org/10.17600/16004700) expedition on the RV Antea. We are grateful to the cGaptain and crew;; to the chief scientist H. Magalon (ULR) for her great efforts to make the expedition possible, for specimens export permits, and for the invitation to join the $\mathrm{MAD}_{\bar{i}}$; and to C. Payri (IRD) for supporting travels and scientific discussion. We are grateful to the chief seientists and crtise organisers C. Payri (IRD), C. Fauvelot (IRD) and H. Magalon (ULR) for invitation to join and valuable help with sampling authorisations. The Madang expedition specimens were obtained during the "Our Planet Reviewed" Papua Niugini expedition (http://dx.doi.org/10.17600/12100070) organised by Muséum National d'Histoire Naturelle (MNHN), Pro Natura International (PNI), Institut de Recherche pour le Développement (IRD), and University of Papua New Guinea (UPNG), with Principal Investigators Philippe Bouchet, Claude Payri, and Sarah Samadi. The organiszers acknowledge funding from the Total Foundation, Prince Albert II of Monaco Foundation, Fondation EDF, Stavros Niarchos Foundation, and Entrepose Contracting, and in-kind support from the Divine Word University (DWU). We thank BW Hoeksema (Naturalis), AH Baird (ARC), M Hoogenboom (JCU), Y Zayasu (OIST), ZT Richards (WAM), and DP Thomson (CSIRO) for specimens of Lobophylliidae. We are deeply grateful to the Eeditor and the four anonymous referees for their comments which greatly improved the manuscript.

\section{References}

Addamo, A.M., Vertino, A., Stolarski, J., García-Jiménez, R., Taviani, M., Machordom, A., 2016. Merging scleractinian genera: the overwhelming genetic similarity between solitary Desmophyllum and colonial Lophelia. BMC Evol. Biol. 16, 108. 
Andrews, K.R., Norton, E.L., Fernandez-Silva, I., Portner, E., Goetze, E., 2014. Multilocus evidence for globally distributed cryptic species and distinct populations across ocean gyres in a mesopelagic copepod. Mol. Ecol. 23, 5462-5479.

Appeltans, W., Ahyong, S.T., Anderson, G., Angel, M.V., Artois, T., Bailly, N., Bamber, R., Barber, A., Bartsch, I., Berta, A., Błażewicz-Paszkowycz, M., 2012. The magnitude of global marine species diversity. Curr. Biol. 22, 2189-2202.

Arrigoni, R., Stefani, F., Pichon, M., Galli, P., Benzoni, F., 2012. Molecular phylogeny of the robust clade (Faviidae, Mussidae, Merulinidae, and Pectiniidae): an Indian Ocean perspective. Mol. Phylogenet. Evol. 65, 183193.

Arrigoni, R., Terraneo, T.I., Galli, P., Benzoni, F., 2014a. Lobophylliidae (Cnidaria, Scleractinia) reshuffled: pervasive non-monophyly at genus level. Mol. Phylogenet. Evol. 73, 60-64.

Arrigoni, R., Richards, Z.T., Chen, C.A., Baird, A.H., Benzoni, F., 2014b. Phylogenetic relationships and taxonomy of the coral genera Australomussa and Parascolymia (Scleractinia, Lobophylliidae). Contrib. Zool. 83, $195-215$.

Arrigoni, R., Kitano, Y.F., Stolarski, J., Hoeksema, B.W., Fukami, H., Stefani, F., Galli, P., Montano, S., Castoldi, E., Benzoni, F., 2014c. A phylogeny reconstruction of the Dendrophylliidae (Cnidaria, Scleractinia) based on molecular and micromorphological criteria, and its ecological implications. Zool. Scripta 43, 661-688.

Arrigoni, R., Berumen, M.L., Terraneo, T.I., Caragnano, A., Bouwmeester, J., Benzoni, F., 2015. Forgotten in the taxonomic literature: resurrection of the scleractinian coral genus Sclerophyllia (Scleractinia, Lobophylliidae) from the Arabian Peninsula and its phylogenetic relationships. Syst. Biodivers. 13, 140-163.

Arrigoni, R., Benzoni, F., Terraneo, T.I., Caragnano, A., Berumen, M.L., 2016a. Arrigoni, R., Benzoni, F., Terraneo, T.I., Caragnano, A. and Berumen, M.L., 2016a. Recent origin and semi-permeable species boundaries in the scleractinian coral genus Stylophora from the Red Sea. Sci. Rep. 6, 34612.

Arrigoni, R., Benzoni, F., Huang, D., Fukami, H., Chen, C.A., Berumen, M.L., Hoogenboom, M., Thomson, D.P., Hoeksema, B.W., Budd, A.F., Zayasu, Y., Terraneo, T.I., Kitano, Y.F., Baird, A.H., 2016b. When forms meet genes: revision of the scleractinian genera Micromussa and Homophyllia (Lobophylliidae) with a description of two new species and one new genus. Contrib. Zool. 85, 387-422.

Arrigoni, R., Berumen, M.L., Chen, C.A., Terraneo, T.I., Baird, A.H., Payri, C., Benzoni, F., $2016 \mathrm{c}$. Species delimitation in the reef coral genera Echinophyllia and Oxypora (Scleractinia, Lobophylliidae) with a description of two new species. Mol. Phylogenet. Evol. 105, 146-159.

Baird, A.H., Guest, J.R., Willis, B.L., 2009. Systematic and biogeographical patterns in the reproductive biology of scleractinian corals. Annu. Rev. Ecol. Evol. Syst. 40, 551-571.

Baird, H.P., Miller, K.J., Stark, J.S., 2011. Evidence of hidden biodiversity, ongoing speciation and diverse patterns of genetic structure in giant Antarctic amphipods. Mol. Ecol. 26, 3439-3454.

Barnosky, A.D., Matzke, N., Tomiya, S., Wogan, G.O., Swartz, B., Quental, T.B., Marshall, C., McGuire, J.L., Lindsey, E.L., Maguire, K.C., Mersey, B., 2011. Has the Earth''s sixth mass extinction already arrived?- Nature $471,51-57$. 
Benzoni, F., Arrigoni, R., Stefani, F., Stolarski, J., 2012a. Systematics of the coral genus Craterastrea (Cnidaria, Anthozoa, Scleractinia) and description of a new family through combined morphological and molecular analyses. Syst. Biodivers. 10, 417-433.

Benzoni, F., Arrigoni, R., Stefani, F., Reijnen, B.T., Montano, S., Hoeksema, B.W., 2012b. Phylogenetic position and taxonomy of Cycloseris explanulata and C. wellsi (Scleractinia Fungiidae): lost mushroom corals find their way home. Contrib. Zool. 81, 125-146.

Bickford, D., Lohman, D.J., Sodhi, N.S., Ng, P.K., Meier, R., Winker, K., Ingram, K.K., Das, I., 2007. Cryptic species as a window on diversity and conservation. Trends Ecol. Evol. 22, 148-155.

Bongaerts, P., Riginos, C., Ridgway, T., Sampayo, E.M., van Oppen, M.J., Englebert, N., Vermeulen, F., Hoegh-Guldberg, O., 2010. Genetic divergence across habitats in the widespread coral Seriatopora hystrix and its associated Symbiodinium. PLoS ONE 5, 10871.

Bouwmeester, J., Baird, A.H., Chen, C.J., Guest, J.R., Vicentuan, K.C., Berumen, M.L., 2015. Multispecies spawning synchrony within scleractinian coral assemblages in the Red Sea. Coral Reefs 34, 65-77.

Budd, A.F., Stolarski, J., 2009. Searching for new morphological characters in the systematics of scleractinian reef corals: comparison of septal teeth and granules between Atlantic and Pacific Mussidae. Acta Zool. $90,142-165$.

Budd, A.F., Fukami, H., Smith, N.D., Knowlton. N., 2012a. Taxonomic classification of the reef coral family Mussidae (Cnidaria: Anthozoa: Scleractinia). Zool. J. Linnean Soc. 166, 465-529.

Budd, A.F., Nunes, F.L., Weil, E., Pandolfi, J.M., 2012b. Polymorphism in a common Atlantic reef coral (Montastraea cavernosa) and its long-term evolutionary implications. Evol. Ecol. 26, 265-290.

Carlon, D.B., Budd, A.F., 2002. Incipient speciation across a depth gradient in a scleractinian coral?. Evolution 56, 2227-2242.

Castresana, J., 2000. Selection of conserved blocks from multiple alignments for their use in phylogenetic analysis. Mol. Biol. Evol. 17, 540-552.

Chadès, I., McDonald-Madden, E., McCarthy, M.A., Wintle, B., Linkie, M., Possingham, H.P., 2008. When to stop managing or surveying cryptic threatened species. Proc. Natl. Acad. Sci. USA 105, 13936-13940.

Chen, C.A., Yu, J.K., 2000. Universal primers for amplification of mitochondrial subunit ribosomal RNAencoding gene in scleractinian corals. Mar. Biotech. 2, 146-153.

Chevalier, J.P., 1975. Les scléractiniaires de la Mélanésie francaise (Nouvelle Calédonie, Iles Chesterfield, Iles Loyauté, Nouvelles Hébrides). Deuxiéme partie. Expéd. Récifs Coralliens Nouvelle Calédonie 7, 1-407.

Coleman, R.R., Eble, J.A., DiBattista, J.D., Rocha, L.A., Randall, J.E., Berumen, M.L., Bowen, B.W., 2016. Regal phylogeography: Range-wide survey of the marine angelfish Pygoplites diacanthus reveals evolutionary partitions between the Red Sea, Indian Ocean, and Pacific Ocean. Mol. Phylogenet. Evol. 100, $243-$ 253.

Combosch, D.J., Vollmer, S.V., 2015. Trans-Pacific RAD-Seq population genomics confirms introgressive hybridization in Eastern Pacific Pocillopora corals. Mol. Phylogenet. Evol. 88, 154-162. 
Cook, L.G., Edwards, R.D., Crisp, M.D., Hardy, N.B., 2010. Need morphology always be required for new species descriptions?. Invertebr. Syst. 24, 322-326.

Cordie, D.R., Budd, A.F., 2016. Histological data in a combined phylogenetic analysis of scleractinian reef corals. J. Morphol. 277, 494-511.

Cowman, P.F., Bellwood, D.R., 2011. Coral reefs as drivers of cladogenesis: expanding coral reefs, cryptic extinction events, and the development of biodiversity hotspots. J. Evol. Biol. 24, 2543-2562.

DeSalle, R., Egan, M.G., Siddall, M., 2005. The unholy trinity: taxonomy, species delimitation and DNA barcoding. Phil. Trans. R. Soc. B 360, 1905-1916.

Drummond, A.J., Suchard, M.A., Xie, D., Rambaut, A., 2012. Bayesian phylogenetics with BEAUti and the BEAST 1.7. Mol. Biol. Evol. 29, 1969-1973.

Dueñas, L.F., Tracey, D.M., Crawford, A.J., Wilke, T., Alderslade, P., Sánchez, J.A., 2016. The Antarctic Circumpolar Current as a diversification trigger for deep-sea octocorals. BMC Evol. Biol 16, 2.

Egea, E., David, B., Choné, T., Laurin, B., Féral, J.P., Chenuil, A., 2016. Morphological and genetic analyses reveal a cryptic species complex in the echinoid Echinocardium cordatum and rule out a stabilizing selection explanation. Mol. Phylogenet. Evol. 94, 207-1220.

Eldredge, N., Thompson, J.N., Brakefield, P.M., Gavrilets, S., Jablonski, D., Jackson, J.B., Lenski, R.E., Lieberman, B.S., McPeek, M.A., Miller III, W., 2005. The dynamics of evolutionary stasis. Paleobiology 31, 133145 .

Farris, J.S., Källersjö, M., Kluge, A.G., Bult, C., 1995. Constructing a significance test for incongruence. Syst. Biol. 44, 570-572.

Fautin, D.G., 2009. Structural diversity, systematic and evolution of cnidae. Toxicon 54, 1054-1064.

Fišer, C., Robinson, C.T., Malard, F., 2018. Cryptic species as a window into the paradigm shift of the species concept. Mol. Ecol. doi:10.1111/mec.14486.

Flot, J.F., Blanchot, J., Charpy, L., Cruaud, C., Licuanan, W.Y., Nakano, Y., Payri, C., Tillier, S., 2011. Incongruence between morphotypes and genetically delimited species in the coral genus Stylophora: phenotypic plasticity, morphological convergence, morphological stasis or interspecific hybridization? BMC Ecol. 11, 22.

Frankowiak, K., Kret, S., Mazur, M., Meibom, A., Kitahara, M.V., Stolarski, J., 2016. Fine-scale skeletal banding can distinguish symbiotic from asymbiotic species among modern and fossil scleractinian corals. PLoS ONE 11, e0147066.

Fukami, H., Budd, A.F., Levitan, D.R., Jara, J., Kersanach, R., Knowlton, N., 2004a. Geographic differences in species boundaries among members of the Montastraea annularis complex based on molecular and morphological markers. Evolution 58, 324-337.

Fukami, H., Budd, A.F., Paulay, G., Sole-Cava, A., Chen, C.A., Iwao, K., Knowlton, N., 2004ㅁ․

Conventional taxonomy obscures deep divergence between Pacific and Atlantic corals. Nature 427, 832-835.

Gélin, P., Postaire, B., Fauvelot, C., Magalon, H., 2017a. Reevaluating species number, distribution and endemism of the coral genus Pocillopora Lamarck, 1816 using species delimitation methods and microsatellites. Mol. Phylogenet. Evol. 109, 430-446. 
Gélin, P., Fauvelot, C., Bigot, L., Baly, J., Magalon, H., 2017b. From population connectivity to the art of striping Russian dolls: the lessons from Pocillopora corals. Ecol. Evol., doi:10.1002/ece3.3747.

Gittenberger, A., Hoeksema, B.W. 2006. Phenotypic plasticity revealed by molecular studies on reef corals of Fungia (Cycloseris) spp. (Scleractinia: Fungiidae) near river outlets. Contrib. Zool. 75, 195-201.

Gittenberger, A., Reijnen, B.T., Hoeksema, B.W., 2011. A molecularly based phylogeny reconstruction of mushroom corals (Scleractinia: Fungiidae) with taxonomic consequences and evolutionary implications for life history traits. Contrib. Zool. 80, 107-132

Goloboff, P.A., Farris, J.S., Nixon, K.C., 2008. TNT, a free program for phylogenetic analysis. Cladistics 24, 774-786.

Hennig, W., 1950. Grundzüge einer Theorie der Phylogenetischen Systematik. Deutscher Zentralverlag, Berlin.

Hennig, W., 1957. Systematik und Phylogenese. In: Hannemann, H.-J. (Ed.), Bericht über die Hundertjahrfeier der Deutschen Entomologischen Gesellschaft Berlin. Akademie Verlag, Berlin, pp. 50-71.

Hennig, W., 1966. Phylogenetic Systematics. University of Illinois Press, Urbana, Illinois.

Herrera, S., Shank, T.M., Sánchez, J.A., 2012. Spatial and temporal patterns of genetic variation in the widespread antitropical deep-sea coral Paragorgia arborea. Mol Ecol. 21, 6053-6067.

Hoeksema, B.W., 2007. Delineation of the Indo-Malayan centre of maximum marine biodiversity: the Coral Triangle. In: Renema, W. (Ed.), Biogeography, time, and place: distributions, barriers, and islands. Springer, Berlin, Germany, pp. 117-178.

Hoeksema, B.W., Waheed, Z., 2011. Initial phase of autotomy in fragmenting Cycloseris corals at Semporna, eastern Sabah, Malaysia. Coral Reefs 30, 1087.

Huang, D., Benzoni, F., Fukami, H., Knowlton, N., Smith, N.D., Budd, A.F., 2014a. Taxonomic classification of the reef coral families Merulinidae, Montastraeidae, and Diploastraeidae (Cnidaria: Anthozoa: Scleractinia). Zool. J. Linnean Soc. 171, 277-355.

Huang, D., Benzoni, F., Arrigoni, R., Baird, A.H., Berumen, M.L., Bouwmeester, J., Chou, L.M., Fukami, H., Licuanan, W.Y., Lovell, E.R., Meier, R., 2014ㅁ․ Towards a phylogenetic classification of reef corals: the IndoPacific genera Merulina, Goniastrea and Scapophyllia (Scleractinia, Merulinidae). Zool. Scripta 43, 531-548.

Huang, D., Licuanan, W.Y., Hoeksema, B.W., Chen, C.A., Ang, P.O., Huang, H., Lane, D.J.W., Vo, S.T., Waheed, Z., Amri, A.Y., Yeemin, T., Chou, L.M. 2015. Extraordinary diversity of reef corals in the South China Sea. Mar. Biodivers. 45, 157-168

Huang, D., Arrigoni, R., Benzoni, F., Fukami, H., Knowlton, N., Smith, N.D., Stolarski, J., Chou, L.M., Budd, A.F., 2016. Taxonomic classification of the reef coral family Lobophylliidae (Cnidaria: Anthozoa: Scleractinia). Zool. J. Linnean Soc. 178, 436-481.

Huang, D., Goldberg, E.E., Chou, L.M., Roy, K., 2017. The origin and evolution of coral species richness in a marine biodiversity hotspot. Evolution, doi:10.1111/evo.13402.

Janiszewska, K., Stolarski, J., Benzerara, K., Meibom, A., Mazur, M., Kitahara, M.V., Cairns, S.D. 2011. A unique skeletal microstructure of the deep-sea micrabaciid scleractinian corals. J. Morphol. 272, $191-203$. 
Jörger, K.M., Schrödl, M., 2013. How to describe a cryptic species? Practical challenges of molecular taxonomy. Front Zool 10, 59.

Jörger, K.M., Schrödl, M., 2014. How to use CAOS software for taxonomy? A quick guide to extract diagnostic nucleotides or amino acids for species descriptions. Spixiana 37, 21-26.

Katoh, K., Standley, D.M., 2013. MAFFT multiple sequence alignment software version 7: improvements in performance and usability. Mol. Biol. Evol. 30, 772-780.

Keith, S.A., Baird, A.H., Hughes, T.P., Madin, J.S., Connolly, S.R., 2013. Faunal breaks and species composition of Indo-Pacific corals: the role of plate tectonics, environment and habitat distribution. Proc. R. Soc. B $280,20130818$.

Kitahara, M.V., Fukami, H., Benzoni, F., Huang, D., 2016. The new systematics of Scleractinia: Integrating molecular and morphological evidence. In: Goffredo, S., Dubinsky, Z. (Eds.), The Cnidaria, past, present and future: The world of Medusa and her sisters. Springer, Berlin, Germany, pp 41-59.

Kitano, Y.F., Benzoni, F., Arrigoni, R., Shirayama, Y., Wallace, C.C., Fukami, H., 2014. A phylogeny of the family Poritidae (Cnidaria, Scleractinia) based on molecular and morphological analyses. PLoS ONE 9, 98406.

Klaus, S., Schubart, C.D., Streit, B., Pfenninger, M., 2010. When Indian crabs were not yet Asianbiogeographic evidence for Eocene proximity of India and Southeast Asia. BMC Evol. Biol. 10, 287.

Knowlton, N., 1993. Sibling species in the sea. Annu. Rev. Ecol. Syst. 24, 189-216.

Ladner, J.T., Palumbi, S.R., 2012. Extensive sympatry, cryptic diversity and introgression throughout the geographic distribution of two coral species complexes. Mol. Ecol. 21, 2224-2238.

Lanfear, R., Calcott, B., Ho, S.Y.W., Guindon, S., 2012. PartitionFinder: combined selection of partitioning schemes and substitution models for phylogenetic analyses. Mol. Biol. Evol. 29, 1695-701.

Leasi, F., Tang, C.Q., De Smet, W.H., Fontaneto, D., 2013. Cryptic diversity with wide salinity tolerance in the putative euryhaline Testudinella clypeata (Rotifera, Monogononta). Zool. J. Linnean Soc. 168, 17-28.

Leprieur, F., Descombes, P., Gaboriau, T., Cowman, P.F., Parravicini, V., Kulbicki, M., Melian, C.J., de Santana, C.N., Heine, C., Mouillot, D., Bellwood, D.R., Pellissier, L., 2016. Plate tectonics drive tropical reef biodiversity dynamics. Nat. Commun. 7, 11461.

Librado, P., Rozas, J., 2009. DnaSP v5: a software for comprehensive analysis of DNA polymorphism data. Bioinformatics 25, 1451-1452.

Lin, M.F., Luzon, K.S., Licuanan, W.Y., Ablan-Lagman, M.C., Chen, C.A., 2011. Seventy-four universal primers for characterizing the complete mitochondrial genomes of scleractinian corals (Cnidaria; Anthozoa). Zool. Stud. 50, 513-524.

Martinez-Baraldés, I., Lopez-González, P.J., Medina, C., 2014. Application of cnidae composition in phylogenetic analyses of North Atlantic and Mediterranean dendrophylliid corals (Anthozoa: Scleractinia).

Invertebr. Syst. 28, 214-230.

McGhee, G.R., 2006. The geometry of evolution: adaptive landscapes and theoretical morphospaces. Cambridge Univ. Press, Cambridge, U.K. 
McPeek, M.A., Gomulkiewicz, R., 2005. Assembling and Depleting Species Richness in Metacommunities. Metacommunities: Spatial dynamics and ecological communities. Springer, Berlin, Germany.

Meulenkamp, J.E., Sissingh, W., 2003. Tertiary palaeogeography and tectonostratigraphic evolution of the Northern and Southern Peri-Tethys platforms and the intermediate domains of the African/Eurasian convergent plate boundary zone. Palaeogeogr. Palaeoclimatol. Palaeoecol. 196, 209-228.

Mora, C., Tittensor, D.P., Adl, S., Simpson, A.G., Worm, B., 2011. How many species are there on Earth and in the ocean?- PLoS Biol. 9, 1001127.

Obura, D., 2012. The diversity and biogeography of Western Indian Ocean reef-building corals. PloS ONE $7,45013$.

Obura, D.O., 2016. An Indian Ocean centre of origin revisited: Palaeogene and Neogene influences defining a biogeographic realm. J. Biogeogr. 43, 229-242.

Oku, Y., Naruse, T., Fukami, H., 2017. Morpho-molecular evidence for polymorphism in the mushroom coral Cycloseris hexagonalis (Scleractinia: Fungiidae), with a new phylogenetic position and the establishment of a new genus for this species. Zoolegic. Sci. 34, 242-251.

Okubo, N., 2016. Restructuring the traditional suborders in the order Scleractinia based on embryogenetic morphological characteristics. Zool. Sci. 33, 116-123.

Okubo, N., Mezaki, T., Nozawa, Y., Nakano, Y., Lien, Y.T., Fukami, H., Hayward, D.C., Ball, E.E., 2013. Comparative embryology of eleven species of stony corals (Scleractinia). PLoS ONE 8, e84115.

Okubo, N., 2016. Restructuring the traditional suborders in the order Seleractinia based on embryogenetic morphological characteristics. Zoologic. Sei. 33, 116-123.

Pfenninger, M., Schwenk, K., 2007. Cryptic animal species are homogeneously distributed among taxa and biogeographical regions. BMC Evol. Biol. 7, 121.

Pinzón, J. H., Sampayo, E., Cox, E., Chauka, L.J., Chen, C.A., Voolstra, C.R., LaJeunesse, T.C., 2013. Blind to morphology: genetics identifies several widespread ecologically common species and few endemics among Indo-Pacific cauliflower corals (Pocillopora, Scleractinia). J. Biogeogr. 40, 1595-1608.

Posada, D., Crandall, K.A., 1998. Modeltest: testing the model of DNA substitution. Bioinformatics 14, $817-818$.

Rambaut, A., 2012. FigTree 1.4. http://tree.bio.ed.ac.uk/software/figtree/

Rambaut, A., Suchard, M.A., Xie, D., Drummond, A.J., 2014. Tracer v1.6. http://beast.bio.ed.ac.uk/Tracer/

Richards, Z.T., Berry, O., van Oppen, M.J., 2016. Cryptic genetic divergence within threatened species of Acropora coral from the Indian and Pacific Oceans. Conserv. Genet. 17, 577-591.

Rissler, L.J., Apodaca, J.J., 2007. Adding more ecology into species delimitation: ecological niche models and phylogeography help define cryptic species in the black salamander (Aneides flavipunctatus). Syst. Biol. 56, 924-942.

Ronquist, F., Teslenko, M., van der Mark, P., Ayres, D.L., Darling, A., Höhna, S., Barget, B., Liu, L., Suchard, M.A., Huelsenbeck, J.P., 2012. MrBayes 3.2: efficient Bayesian phylogenetic inference and model choice across a large model space. Syst. Biol. 61, 539-542. 
Rosser, N.L., 2015. Asynchronous spawning in sympatric populations of a hard coral reveals cryptic species and ancient genetic lineages. Mol. Ecol. 24, 5006-5019.

Sáez, A.G., Probert, I., Geisen, M., Quinn, P., Young, J.R., Medlin, L.K., 2003. Pseudo-cryptic speciation in coccolithophores. Proc. Natl. Acad. Sci. U.S.A. 100, 7163-7168.

Sáez, A.G., Lozano, E., 2005. Body doubles. Nature 433, 111.

Santodomingo, N., Wallace, C.C., Johnson, K.G., 2015. Fossils reveal a high diversity of the staghorn coral genera Acropora and Isopora (Scleractinia: Acroporidae) in the Neogene of Indonesia. Zool. J. Linn. Soc. 175, 677$\underline{763}$

Sarkar, I.N., Planet, P.J., DeSalle, R., 2008. CAOS software for use in character-based DNA barcoding. Mol. Ecol. Resour. 8, 1256-1259.

Scheffers, B.R., Joppa, L.N., Pimm, S.L., Laurance, W.F., 2012. What we know and don't know about Earth's missing biodiversity. Trends Ecol. Evol. 27, 501-510.

Schettino, A., Turco, E., 2011. Tectonic history of the western Tethys since the Late Triassic. Geol. Soc. Am. Bull. 123, 89-105.

Schmidt-Roach, S., Lundgren, P., Miller, K.J., Gerlach, G., Noreen, A.M.E., Andreakis, N., 2013a. Assessing hidden species diversity in the coral Pocillopora damicornis from Eastern Australia. Coral Reefs 32, 161172.

Schmidt-Roach, S., Miller, K.J., Andreakis, N., 2013b. Pocillopora aliciae: a new species of scleractinian coral (Scleractinia, Pocilloporidae) from subtropical Eastern Australia. Zootaxa 3626, 576-582.

Schmidt-Roach, S., Miller, K.J., Lundgren, P., Andreakis, N., 2014. With eyes wide open: a revision of species within and closely related to the Pocillopora damicornis species complex (Scleractinia; Pocilloporidae) using morphology and genetics. Zool. J. Linnean Soc. 170, 1-33.

Schönrogge, K., Barr, B., Wardlaw, J.C., Napper, E., Gardner, M.G., Breen, J., Elmes, G.W., Thomas, J.A., 2002. When rare species become endangered: cryptic speciation in myrmecophilous hoverflies. Biol. J. Linn. Soc. 75, 291-300.

Shank, T.M., Black, M.B., Halanych, K.M., Lutz, R.A., Vrijenhoek, R.C. 1999. Miocene radiation of deepsea hydrothermal vent shrimp (Caridea: Bresiliidae): evidence from mitochondrial Cytochrome Oxidase Subunit I. Mol Phylogenet Evol. 13, 244-254.

Simpson, C., Kiessling, W., Mewis, H., Baron-Szabo, R.C. and Müller, J., 2011. Evolutionary diversification of reef corals: a comparison of the molecular and fossil records. Evolution 65, 3274-3284 Sorenson, M.D., Franzosa, E.A., 2007. TreeRot. Version 3. http://people.bu.edu/msoren/TreeRot.html Souter, P., 2010. Hidden genetic diversity in a key model species of coral. Mar. Biol. 157, 875-885. Stefani, F., Benzoni, F., Yang, S.Y., Pichon, M., Galli, P., Chen, C.A., 2011. Comparison of morphological and genetic analyses reveals cryptic divergence and morphological plasticity in Stylophora (Cnidaria, Scleractinia). Coral Reefs 30, 1033-1049.

Stolarski, J., Kitahara, M.V., Miller, D.J., Cairns, S.D., Mazur, M., Meibom, A., 2011. The ancient evolutionary origins of Scleractinia revealed by azooxanthellate corals. BMC Evol. Biol. 11, 316. 
Stolarski, J., Bosellini, F.R., Wallace, C.C., Gothmann, A., Mazur, M., Domart-Coulon, I., Gutner-Hoch, E., Neuser, R.D., Levy, O., Shemesh, A., Meibom, A., 2016. A unique coral biomineralization pattern has resisted 40 million years of major ocean chemistry change. Sci. Rep. 6, 27579.

Strauss, D., Sadler, P.M., 1989. Classical confidence intervals and Bayesian probability estimates for ends of local taxon ranges. Math. Geol. 21, 411-427.

Strugnell, J.M., Rogers, A.D., Prodöhl, P.A., Collins, M.A., Allcock, A.L., 2008. The thermohaline expressway: the Southern Ocean as a centre of origin for deep-sea octopuses. Cladistics 24, 853-860.

Suzuki, G., Keshavmurthy, S., Hayashibara, T., Wallace, C.C., Shirayama, Y., Chen, C.A., Fukami, H., 2016. Genetic evidence of peripheral isolation and low diversity in marginal populations of the Acropora hyacinthus complex. Coral Reefs 35, 1419-1432.

Swofford, D.L., 2003. PAUP. Phylogenetic Analysis Using Parsimony (and other methods). Version 4. Sinauer Associates, Sunderland, Massachusetts.

Takabayashi, M., Carter, D.A., Loh, W.K.W., Hoegh-Guldberg, O., 1998. A coralspecific primer for PCR amplifications of the internal transcribed spacer region in ribosomal DNA. Mol. Ecol. 7, 928-930.

Todd, P.A., 2008. Morphological plasticity in scleractinian corals. Biol. Rev. 83, 315-337.

Veron, J.E.N., 2000. Corals of the World. Australian Institute of Marine Science, Townsville, Australia.

Veron, J.E.N., 2002. New species described in Corals of the World. Australian Institute of Marine Science, Townsville, Australia.

Veron, J.E.N., Pichon, M., 1976. Scleractinia of Eastern Australia, I: Families Thamnasteriidae, Astrocoeniidae, Pocilloporidae. Monogr. Ser. Aust. Inst. Mar. Sci. 1, 1-86.

Veron, J.E.N., Pichon, M., 1980. Scleractinia of Eastern Australia, III: Families Agariciidae, Siderastreidae, Fungiidae, Oculinidae, Merulinidae, Mussidae, Pectiniidae, Caryophylliidae, Dendrophylliidae. Monogr. Ser. Aust. Inst. Mar. Sci. 4, 1-433.

Veron, J., Stafford-Smith, M., DeVantier, L., Turak, E., 2015. Overview of distribution patterns of zooxanthellate Scleractinia. Front. Mar. Sci. 1, 1-19.

Vogler, A.P., Monaghan, M.T., 2007. Recent advances in DNA taxonomy. J. Zoolog. Syst. Evol. Res. 45, $1-10$.

Wallace, C., 1999. Staghorn corals of the world: a revision of the genus Acropora. CSIRO publishing, Camberra, Australia.

Wallace, C.C., Rosen, B.R., 2006. Diverse staghorn corals (Acropora) in high-latitude Eocene assemblages: Implications for the evolution of modern diversity patterns of reef corals. Proc. Biol. Sci.273, 975982.

Warner, P.A., Oppen, M.J., Willis, B.L., 2015. Unexpected cryptic species diversity in the widespread coral Seriatopora hystrix masks spatial-genetic patterns of connectivity. Mol. Ecol. 24, 2993-3008.

White, T.J., Bruns, T., Lee, S., Taylor, J., 1990. Amplification and direct sequencing of fungal ribosomal RNA genes for phylogenetics. In: Innis, M.A., Gelfand, D.H., Sninsky, J.J., White, T.J. (Eds.), PCR Protocols. A Guide to Methods and Application. Academic Press Inc., San Diego, California, pp. 315-322. 
Wiley, E.O., 1981. Phylogenetics. The Theory and Practice of Phylogenetic Systematics. J. Wiley and Sons, New York.

Winker, K., 2005. Sibling species were first recognized by William Derham (1718). Auk 122, 706-707.

Zachos, J.C., Shackleton, N.J., Revenaugh, J.S., Pälike, H., Flower, B.P., 2001. Climate response to orbital forcing across the Oligocene-Miocene boundary. Science 292, 274-278.

Zwickl, D.J., 2006. GARLI: genetic algorithm for rapid likelihood inference.

http://www.bio.utexas.edu/faculty/antisense/garli/Garli.html/

\section{Tables and Figures}

Table 1 List of species, voucher, molecular clade to which they belong, collection locality, and accession numbers of the COI, 12S, ATP6-NAD4, NAD3-NAD5, histone H3, and ITS included in the molecular phylogeny. Newly-obtained sequences are in bold

Table 2 Statistics for each locus used in the analysis. Number of sites (S), Number of variable sites (\%) (SV), Number of parsimony-informative sites (\%) (SPI), Haplotype diversity (HD), Nucleotide diversity (ND), GCcontent (GC)

Table 3 Pairwise comparisons of genetic distance values (p-distance) within and between genera of Lobophylliidae based on the combined dataset (COI, 12S, ATP6-NAD4, NAD3-NAD5, histone H3, ITS). Intergeneric pairwise comparisons of genetic distance are in bold, intrageneric genetic distances are indicated along the diagonal, and standard deviations are reported either in brackets or on the upper right hand portions for each set of comparisons. n.c. $=$ not calculable

Table 4 Estimated divergence times (Ma) with 95\% highest posterior density (HPD) distribution for genera of Lobophylliidae and the main nodes of the molecular phylogeny shown in Fig. 4. The posterior probabilities (pp) $\geq$ 0.70 obtained in BEAST are reported

Fig. 1. Paraechinophyllia variabilis gen. et sp. nov. in situ. (a) Holotype, MNHN-IK-2014-250, at Mayotte Island. (b) Paratype, MNHN-IK-2014-251, at Mayotte Island. (c) KAUST SA0922, at Magna, Saudi Arabia. (d) KAUST SA0021, at Al Lith, Saudi Arabia. (e) Paratype, MNHN-IK-2014-247, at Al Mukallah (same as in 2d), Yemen. (f) KAUST SA0794, at Jaz'air Silah, Saudi Arabia. (g) KAUST SA0944, at Magna, Saudi Arabia. (h) KAUST SA1023, at Magna, Saudi Arabia.

Fig. 2. Paraechinophyllia variabilis gen. et sp. nov. corallite macromorphology. (a) Holotype, MNHN-IK2014-250 (same as in 1a). (b) Paratype, MNHN-IK-2014-251 (same as in 1b). (c) KAUST SA0922 (same as in 1c). (d) KAUST SA0021 (same as in 1d). (e) Paratype, MNHN-IK-2014-247 (same as in 1e). (f) KAUST SA0794 (same as in 1f). (g) KAUST SA0944 (same as in 1g). (h) KAUST SA1023 (same as in 1h).

Fig. 3. Type material Paraechinophyllia variabilis gen. et sp. nov. (a) Holotype, MNHN-IK-2014-250 (same as in 1a and 2a). (b) Paratype, MNHN-IK-2014-251 (same as in 1b and 2b). (c) Paratype, MNHN-IK-2014252. (d) Paratype, MNHN-IK-2014-247 (same as in 1e and 2e).

Fig. 4. Phylogeny reconstruction of the family Lobophylliidae, showing the position of Paraechinophyllia variabilis gen. et sp. nov (clade K). (a) Multi-locus fossiltime-calibrated phylogeny reconstruction inferred from the 
concatenated dataset (COI, 12S, ATP6-NAD4, NAD3-NAD5, histone H3, and ITS, 3965 bp), analysed using BEAST. The violet circle I marks the node that was time-constrained with fossil (the stratigraphically oldest fossil occurrence of Lobophyllia, 19-31.3 Mya) as described in the text. Node values are posterior probabilities ( $\geq 0.7)$ and violet bars display the 95\% highest posterior density (HPD) interval of node ages. (b) Strict consensus of 19 maximum parsimony trees based on 46 morphological characters, analysed using TNT. Values above nodes are Bremer decay index $(\geq 2)$ and below nodes are maximum parsimony bootstrap $(\geq 50)$. Clades from A to J are labelled and coloured according to Arrigoni et al. (2014a) and Huang et al. (2016).

Fig. 5. Microstructural characteristics of Paraechinophyllia variabilis gen. et sp. nov. robust morphotype MNHN IK-2014-250 (a-c) and less robust MNHN IK-2014-252 (d-f) in direct comparison to Oxypora (O. lacera, gi) and Echinophyllia (E. aspera, j-m); optical transmitted light microscopy (insets in right-upper corners of a,d,g,j show low magnification images of sections). In more robust coralla of MNHN IK-2014-250 lower order septa show clusters of Rapid Accretion Deposits (RAD's) with projections extending toward the septal faces (red outlined white arrows in b). Such lateral projections of RAD's can also be observed in lower order septa of less robust O. lacera and E. aspera (h, k). Septa of less robust MNHN IK-2014-252 and higher order septa of O. lacera and E. aspera have RAD's frequently in a form of straight or wavy mid-septal zone (red arrows, see e, h, j, l). Sectioned septal teeth show elliptical clusters of RAD's (dashed red outline in k). Thickening deposits (TD's) consists of well delineated, slender (typically longer than $100 \mu \mathrm{m}$ ) bundles of fibers, ca. $10 \mu \mathrm{m}$ in diameter (c, i, m, polariszed light). Thickness of fibre boundless is consistent with diameter of microtuberculate texture on septal faces (compare Fig. 6i, 7g).

Fig. 6. Microstructural characteristics of robust morphotype of Paraechinophyllia variabilis gen. et sp. nov. (MNHN IK-2014-250) in SEM: natural surfaces (a, d, f, i) and polished and delicately etched sections (b, c, e, g, h, j). Distinct tooth show several RAD's regions (d, f, white arrows). Septal faces (especially in distal region) are covered with microtuberculate texture ca. $10 \mu \mathrm{m}$ in diameter (i). Rapid Accretion Deposits (RAD's) in more robust septa (also within well differentiated septal teeth) form projections extending toward the septal faces (red outlined arrows in e), however between such regions RAD's typically form continuous mid-septal line (red arrow in b). TD's show regular growth banding (red arrows in j). Mid-septal zone in longitudinal section of septum (c, h).

Fig. 7. Microstructural characteristics of less robust morphotype of Paraechinophyllia variabilis gen. et sp. nov. (MNHN IK-2014-252) in SEM: natural surfaces (a, c, e, g) and polished and delicately etched sections (b, d, f, h). Distinct tooth on lower cycle septa show several RAD's regions (d, white arrows). Septal faces are covered with microtuberculate texture ca. $10 \mu \mathrm{m}$ in diameter (e, g). Rapid Accretion Deposits (RAD's) in less robust septa form continuous mid-septal line (red arrows in e, f), whereas in slightly more robust ones they form clusters with projections extending toward the septal faces as in robust morphotypes of $\mathrm{P}$. variabilis (red outlined arrows in d). TD's show regular growth banding (red arrows in h).

\section{Supporting Information}

Additional Supporting Information may be found in the online version of this article:

Data S1. Nexus data file containing the aligned molecular data matrix (COI, 12S, ATP6-NAD3, NAD4NAD5, histone H3, and ITS) used in this study. 
Data S2. Output file of PartitonFinder to identify the best partition scheme and nucleotide substitution models.

Data S3. Nexus data file containing the aligned morphological data matrix (46 characters) used in this study.

Figure S1. Bayesian phylogeny reconstruction of the family Lobophylliidae for each individual gene dataset (COI, 12S, ATP6-NAD3, NAD4-NAD5, histone H3, and ITS). Numbers above branches indicate nodal support by means of Bayesian posterior probabilities ( $>0.8)$, Maximum Likelihood bootstrap support $(>0.7)$, and Maximum Parsimony bootstrap support (>50).

Figure S2. Phylogenetic character mapping of the 46 analysed morphological characters on the molecular phylogeny reconstruction of Lobophylliidae. Ancestral states have been reconstructed using maximum parsimony and calculated using MESQUITE. Character states are according to Huang et al. (2016), see Appendices 1 and 2.

Figure S3. Microstructural characteristics of robust morpotype of Echinophyllia orpheensis (morphologically very similar to E. aspera) in optical transmitted light microscopy and SEM images. Lower order septa in regions of teeth development show larger clusters of Rapid Accretion Deposits (RAD's) with projections extending toward the septal faces (red outlined white arrows in b); SEM images of these clusters on etched sections in e, f. Higher order septa show RAD's locally arranged as continuous mid-septal zone. Thickening deposits (TD's) consists of well delineated, slender (typically longer than $100 \mu \mathrm{m}$ ) bundles of fibers, ca. $10 \mu \mathrm{m}$ in diameter (d, polariszzed light).

Table S1. Pairwise comparisons of genetic distance values (p-distance) within and between genera of Lobophylliidae based on the individual gene datasets (COI, 12S, ATP6-NAD4, NAD3-NAD5, histone H3, ITS). Intergeneric pairwise comparisons of genetic distance are in bold, intrageneric genetic distances are indicated along the diagonal, and standard deviations are reported either in brackets or on the upper right hand portions for each set of comparisons. n.c. $=$ not calculable

Appendix 1. List of morphological characters, character states, and parsimony model used for the morphological phylogenetic analysis.

Appendix 2a. Morphological character-state matrix based on characters presented in Appendix 1 (characters 1-23). * new data provided in this study; ? missing data; - not applicable.

Appendix 2b. Morphological character-state matrix based on characters presented in Appendix 1 (characters 24-46). ? missing data; - not applicable. 
Table 1

List of species, voucher, molecular clade to which they belong, collection locality, and accession numbers of the COI, 12S, ATP6-NAD4, NAD3-NAD5, Histone H3, and ITS included in the molecular phylogeny. Newly-obtained sequences are in bold

\begin{tabular}{|c|c|c|c|c|c|c|c|c|c|c|c|}
\hline $\begin{array}{l}\text { Vouc } \\
\text { her }\end{array}$ & $\begin{array}{l}\text { Oth } \\
\text { er }\end{array}$ & Genus & Species & $\begin{array}{l}\text { Molec } \\
\text { ular } \\
\text { clade }\end{array}$ & $\begin{array}{l}\text { Locali } \\
\text { ty }\end{array}$ & $\mathrm{COI}$ & $12 \mathrm{~S}$ & $\begin{array}{l}\text { ATP6- } \\
\text { NAD4 }\end{array}$ & $\begin{array}{l}\text { NAD3 } \\
- \\
\text { NAD5 }\end{array}$ & $\begin{array}{l}\text { Histone } \\
\text { H3 }\end{array}$ & ITS \\
\hline MNH & & & & & $\begin{array}{l}\text { Gulf } \\
\text { of }\end{array}$ & & & & & & \\
\hline N-IK- & M & Eryptophyll & & & Aden, & MF426 & MF42 & MF42 & MF53 & MF426 & MF426 \\
\hline 2014- & U1 & taparaechin & & & Yeme & $\overline{191 X X}$ & $\overline{6177 X}$ & $\overline{6037 X}$ & $\overline{9828 X}$ & $\overline{114 X X}$ & $\overline{095 X X}$ \\
\hline 247 & 32 & ophyllia & variabilis & K & $\begin{array}{l}\mathrm{n} \\
\text { Gulf }\end{array}$ & $\mathrm{X}$ & XX & XX & XX & $\mathbf{X}$ & $\mathrm{X}$ \\
\hline MNH & & & & & of & & & & & & \\
\hline N IK- & M & $\underline{\text { Paraechino }}$ & & & Aden, & MF426 & $\underline{\text { MF42 }}$ & $\underline{\text { MF42 }}$ & $\underline{\text { MF53 }}$ & MF426 & $\underline{\text { MF426 }}$ \\
\hline 2014- & U1 & phylliacryp & & & Yeme & $\underline{192 X X}$ & $\underline{6178 X} \times$ & $\overline{6038 X}$ & $\underline{9829 X}$ & $\underline{115 X X}$ & $\underline{096 \times X}$ \\
\hline $\begin{array}{l}252 \\
\text { MNH }\end{array}$ & 65 & $\begin{array}{l}\text { tophyllia } \\
\text { Paraechino }\end{array}$ & variabilis & K & $\mathrm{n}$ & $\mathbf{X}$ & $X X$ & $X X$ & XX & & $\mathbf{X}$ \\
\hline N-IK- & M & phylliacryp & & & Mayot & MF426 & MF42 & MF42 & MF53 & MF426 & $\underline{\text { MF426 }}$ \\
\hline 2014- & Y0 & tophyllia & & & & $193 X X$ & $\underline{6179 x}$ & $\underline{6039} \times$ & 9830X & $116 \times X$ & $\underline{097 X X}$ \\
\hline $\begin{array}{l}251 \\
\text { MNH }\end{array}$ & 50 & Paraechino & variabilis & K & Island & $\bar{x}$ & $\overline{X X}$ & $\overline{X X}$ & $\overline{X X}$ & $\bar{X}$ & $\bar{x}$ \\
\hline N IK- & M & $\overline{\text { phyllia eryp }}$ & & & Mayot & MF426 & MF42 & $\underline{\text { MF42 }}$ & MF53 & MF426 & MF426 \\
\hline 2014- & Y2 & tophyllia & & & te & 194XX & $\underline{6180 x}$ & $6040 \times$ & 9831X & $117 X X$ & $\underline{098} \times X$ \\
\hline 250 & 36 & & variabilis & $\mathrm{K}$ & Island & $\bar{x}$ & $\overline{X X}$ & $\overline{X X}$ & $\overline{X X}$ & $\bar{x}$ & $\bar{x}$ \\
\hline KAU & & Paraechino & & & Red & & & & & & \\
\hline ST & & phyllia eryp & & & Sea, & MF426 & $\underline{\text { MF42 }}$ & $\underline{\text { MF42 }}$ & $\underline{\text { MF53 }}$ & MF426 & $\underline{\text { MF426 }}$ \\
\hline SA00 & & ophyllia & & & Saudi & 195XX & $\underline{6181 X}$ & $\overline{6041 X}$ & $\underline{9832 X}$ & 118XX & $\overline{099 \times X}$ \\
\hline 21 & & & variabilis & $\mathrm{K}$ & Arabia & $\bar{X}$ & $\mathrm{XX}$ & $\overline{X X}$ & $\overline{X X}$ & $\mathrm{X}$ & $\mathrm{X}$ \\
\hline $\begin{array}{l}\text { KAU } \\
\text { ST }\end{array}$ & & $\frac{\text { Paraechino }}{\text { phyllia } \operatorname{cryp}}$ & & & $\begin{array}{l}\text { Red } \\
\text { Sea, }\end{array}$ & MF426 & MF42 & MF42 & MF53 & MF426 & MF426 \\
\hline SA10 & & tophyllia & & & Saudi & 199XX & $6185 X$ & $6045 X$ & $9836 \mathrm{X}$ & $122 X X$ & $103 X X$ \\
\hline 23 & & & variabilis & K & Arabia & $\bar{x}$ & $\overline{X X}$ & $\overline{X X}$ & $\overline{X X}$ & $\bar{x}$ & $\bar{x}$ \\
\hline KAU & & Paraechino & & & Red & & & & & & \\
\hline ST & & $\overline{\text { phyllia Cryp }}$ & & & Sea, & MF426 & $\underline{\text { MF42 }}$ & MF42 & MF53 & MF426 & MF426 \\
\hline SA07 & & tophyllia & & & Saudi & $\overline{196 \times X}$ & $\overline{6182 x}$ & $\overline{6042 X}$ & $\overline{9833 x}$ & $\overline{119 X X}$ & $\overline{100 \times X X}$ \\
\hline 94 & & & variabilis & K & Arabia & $\bar{x}$ & $\overline{X X}$ & $\overline{X X}$ & $\overline{X X}$ & $\bar{X}$ & $\bar{x}$ \\
\hline KAU & & Paraechino & & & Red & & & & & & \\
\hline ST & & phyllia eryp & & & Sea, & MF426 & MF42 & MF42 & MF53 & MF426 & $\underline{\text { MF426 }}$ \\
\hline SA09 & & tophyllia & & & Saudi & $\overline{197 X X}$ & $6183 X$ & $6043 X$ & $\overline{9834 X}$ & $\overline{120 X X}$ & $\overline{101 X X}$ \\
\hline 22 & & & variabilis & $\mathrm{K}$ & Arabia & $\bar{X}$ & $\overline{X X}$ & $\overline{X X}$ & $\overline{X X}$ & $\bar{X}$ & $\bar{X}$ \\
\hline KAU & & Paraechino & & & Red & & & & & & \\
\hline ST & & phyllia eryp & & & Sea, & MF426 & $\underline{\text { MF42 }}$ & $\underline{\text { MF42 }}$ & MF53 & MF426 & MF426 \\
\hline SA09 & & tophylliat & & & Saudi & $198 \times X$ & $6184 X$ & $6044 X$ & $9835 x$ & $121 X X$ & $102 \times X$ \\
\hline 44 & & & variabilis & K & Arabia & $\bar{X}$ & $\overline{\mathrm{XX}}$ & $\overline{X X}$ & $\overline{\mathrm{XX}}$ & $\bar{X}$ & $\bar{X}$ \\
\hline & & Paraechino & & & & MF426 & $\underline{\text { MF42 }}$ & $\underline{\text { MF42 }}$ & $\underline{\text { MF53 }}$ & MF426 & $\underline{\text { MF426 }}$ \\
\hline MD2 & & $\overline{\text { phyllia Cryp }}$ & & & Madag & $\underline{200 \times X}$ & $\overline{6186 X}$ & $\overline{6046 X}$ & $\overline{9837 X}$ & $\overline{123 X X}$ & $\overline{104 X X}$ \\
\hline 39 & & tophyllia & variabilis & K & ascar & $\bar{X}$ & $\overline{X X}$ & $\overline{X X}$ & $\overline{X X}$ & $\bar{X}$ & $\bar{X}$ \\
\hline & & Paraechino & & & & MF426 & $\underline{\text { MF42 }}$ & $\underline{\text { MF42 }}$ & $\underline{\text { MF53 }}$ & MF426 & MF426 \\
\hline MD2 & & $\overline{\text { phyllia Eryp }}$ & & & Madag & $\underline{201 X X}$ & $\overline{6187 X}$ & $\overline{6047 X}$ & $\overline{\mathbf{9 8 3 8 X}}$ & $\overline{124 X X}$ & $\overline{105 X X}$ \\
\hline 40 & & ophyllia & variabilis & K & ascar & $\bar{X}$ & $\overline{X X}$ & $\overline{X X}$ & $\overline{X X}$ & & $\bar{X}$ \\
\hline & & Paraechino & & & & $\underline{\text { MF426 }}$ & MF42 & MF42 & MF53 & MF426 & MF426 \\
\hline MD2 & & phyllia eryp & & & Madag & 202XX & $\overline{6188 X}$ & $\overline{6048 X}$ & $\overline{9839 x}$ & $\underline{125 X X}$ & $\overline{106 \times X}$ \\
\hline 41 & & ophyllia & variabilis & K & ascar & & $\overline{X X}$ & $\overline{X X}$ & $\overline{X X}$ & & \\
\hline & & Paraechino & & & & MF426 & MF42 & MF42 & MF53 & MF426 & MF426 \\
\hline MD2 & & $\overline{\text { phyllia Eryp }}$ & & & Madag & $\overline{203 X X}$ & $\overline{6189 \times}$ & $\overline{6049 \times}$ & $\overline{9840 \times}$ & $\overline{126 \times X X}$ & $\overline{107 X X}$ \\
\hline 65 & & ophyllia & variabilis & $\mathrm{K}$ & ascar & & $\overline{X X}$ & $\overline{X X}$ & $\overline{X X}$ & & \\
\hline $\mathrm{AM}$ & & & lordhowen & & Austra & LN875 & MF42 & MF42 & MF53 & LN875 & LN876 \\
\hline MHO & & Micromussa & sis & A & lia & 913 & $6152 X$ & $6080 \times$ & $9870 \mathrm{X}$ & 992 & 069 \\
\hline
\end{tabular}




\begin{tabular}{|c|c|c|c|c|c|c|c|c|c|c|}
\hline \multicolumn{11}{|l|}{$\begin{array}{l}42 \\
\text { UNI }\end{array}$} \\
\hline MIB & & & & French & & $\underline{\text { MF42 }}$ & $\underline{\text { MF42 }}$ & MF53 & & \\
\hline GA15 & & & & Polyne & LN875 & $\underline{6151 X}$ & $\underline{6079 x}$ & $\underline{9869} \times$ & LN875 & LN876 \\
\hline 0 & Micromussa & pacifica & A & $\begin{array}{l}\text { sia } \\
\text { Gulf }\end{array}$ & 888 & XX & XX & XX & 966 & 044 \\
\hline MNH & & & & of & & & & & & \\
\hline N IK- & & & & Aden, & & $\underline{\text { MF42 }}$ & $\underline{\text { MF42 }}$ & $\underline{\text { MF53 }}$ & & \\
\hline 2012- & & & & Yeme & LN875 & $\underline{6153} X$ & $\underline{6081 X}$ & $\underline{9871 X}$ & LN875 & LN876 \\
\hline $\begin{array}{l}16046 \\
\text { SMB }\end{array}$ & Micromussa & indiana & A & $\mathrm{n}$ & 886 & $\mathrm{XX}$ & XX & $\mathbf{X X}$ & 963 & 042 \\
\hline L & & & & & & MF42 & MF42 & $\underline{\text { MF53 }}$ & & \\
\hline Cni- & & amakusen & & & LN875 & $\underline{6150 x}$ & $\overline{\underline{6078 X}}$ & $\overline{9868 X}$ & LN875 & LN876 \\
\hline $\begin{array}{l}11060 \\
\text { RMN }\end{array}$ & Micromussa & sis & A & Japan & 880 & $\begin{array}{l}\text { XX } \\
\text { MF42 }\end{array}$ & $\begin{array}{l}\text { XX } \\
\text { MF42 }\end{array}$ & XX & 956 & 036 \\
\hline $\mathrm{H}$ & & multipunct & & Malay & LN875 & $6149 x$ & $6077 X$ & $9867 X$ & LN875 & LN876 \\
\hline 40077 & Micromussa & ata & A & sia & 898 & $\begin{array}{l}\text { XX } \\
\text { MF42 } \\
\end{array}$ & $\begin{array}{l}\mathrm{XX} \\
\text { MF42 }\end{array}$ & $\begin{array}{l}\text { XX } \\
\text { MF53 } \\
\end{array}$ & 976 & 054 \\
\hline AM & Homophylli & bowerban & & Austra & LN875 & $\underline{6147 X}$ & $\underline{6062 X}$ & $\underline{9853} \times$ & LN875 & LN876 \\
\hline 4629 & $a$ & $k i$ & B & lia & 865 & $\begin{array}{l}\text { XX } \\
\text { MF42 } \\
\end{array}$ & $\begin{array}{l}\text { XX } \\
\text { MF42 } \\
\end{array}$ & $\begin{array}{l}\text { XX } \\
\text { MF53 } \\
\end{array}$ & 940 & 021 \\
\hline $\begin{array}{l}\text { AM } \\
4631\end{array}$ & $\begin{array}{l}\text { Homophylli } \\
a\end{array}$ & australis & B & $\begin{array}{l}\text { Austra } \\
\text { lia }\end{array}$ & $\begin{array}{l}\text { LN875 } \\
854\end{array}$ & $\overline{\frac{6148 X}{X X}}$ & $\overline{\frac{6063 X}{X X}}$ & $\overline{\frac{9854 X}{X X}}$ & $\begin{array}{l}\text { LN875 } \\
929\end{array}$ & $\begin{array}{l}\text { LN876 } \\
010\end{array}$ \\
\hline \multicolumn{11}{|l|}{ UNI } \\
\hline MIB & & & & Aden, & & $\underline{\text { MF42 }}$ & $\underline{\text { MF42 }}$ & $\underline{\text { MF53 }}$ & & \\
\hline MU1 & Sclerophylli & & & Yeme & HE654 & $\underline{6157 X}$ & $\underline{6085 X}$ & $\underline{9875 X}$ & LK022 & HE648 \\
\hline $\begin{array}{l}61 \\
\text { KAU }\end{array}$ & $a$ & maxima & $\mathrm{C}$ & & 627 & $\mathrm{XX}$ & XX & $\mathrm{XX}$ & 407 & 543 \\
\hline ST & & & & Sea, & & $\underline{\text { MF42 }}$ & $\underline{\text { MF42 }}$ & $\underline{\text { MF53 }}$ & & \\
\hline SA08 & Sclerophylli & margaritic & & Saudi & LM993 & $\underline{6158} \mathrm{X}$ & $\underline{6086} \times$ & $\underline{9876 X}$ & LM993 & LM993 \\
\hline $\begin{array}{l}80 \\
\text { KAU }\end{array}$ & $a$ & ola & $\mathrm{C}$ & Arabia & 330 & $X X$ & XX & XX & 310 & 347 \\
\hline ST & & & & & $\underline{\text { MF426 }}$ & MF42 & MF42 & MF53 & MF426 & $\underline{\text { MF426 }}$ \\
\hline TAU & & & & Austra & $\underline{204 X X}$ & $\underline{6175 X}$ & $\underline{6092 X}$ & $\underline{9882 X}$ & $\underline{127 X X}$ & $\underline{108} \times X$ \\
\hline $\begin{array}{l}263 \\
\text { UNI }\end{array}$ & Moseleya & latistellata & $\mathrm{D}$ & lia & & XX & XX & XX & X & X \\
\hline MIB & & & & & & $\underline{\text { MF42 }}$ & $\underline{\text { MF42 }}$ & $\underline{\text { MF53 }}$ & & \\
\hline DJ28 & Acanthastre & & & Djibou & HF954 & $\underline{6133 X}$ & $\underline{6050 \times}$ & $\underline{9841 X}$ & LK022 & HF954 \\
\hline 8 & $a$ & echinata & E & $\mathrm{ti}$ & 214 & $\overline{X X}$ & $\overline{X X}$ & $\overline{X X}$ & 408 & 301 \\
\hline IRD & & & & New & & MF42 & MF42 & $\underline{\text { MF53 }}$ & & \\
\hline HS30 & Acanthastre & hemprichi & & Caled & HF954 & $\underline{6134 X}$ & $\underline{6051 X}$ & $\underline{9842 X}$ & LK022 & HF954 \\
\hline 65 & $a$ & $i$ & E & onia & 221 & XX & XX & XX & 411 & 309 \\
\hline IRD & & & & New & & $\underline{\text { MF42 }}$ & $\underline{\text { MF42 }}$ & $\underline{\text { MF53 }}$ & & \\
\hline HS31 & Acanthastre & rotundoflo & & Caled & HF954 & $\underline{6135 X}$ & $\underline{6052 X}$ & $\underline{9843 X}$ & LN999 & HF954 \\
\hline 66 & $a$ & ra & E & onia & 216 & $X X$ & $X X$ & $X X$ & 917 & 303 \\
\hline IRD & & & & New & & $\underline{\text { MF42 }}$ & $\underline{\text { MF42 }}$ & $\underline{\text { MF53 }}$ & & \\
\hline HS32 & Acanthastre & subechina & & Caled & HF954 & $\underline{6136} \times$ & $\underline{6053} X$ & $\underline{9844 X}$ & LK022 & HF954 \\
\hline 28 & $a$ & $t a$ & E & onia & 219 & $\overline{X X}$ & $\overline{X X}$ & $\overline{X X}$ & 409 & 304 \\
\hline IRD & & & & New & & MF42 & $\underline{\text { MF42 }}$ & $\underline{\text { MF53 }}$ & & \\
\hline HS32 & Acanthastre & pachysept & & Caled & LN999 & $6137 X$ & $\underline{6054} X$ & $\underline{9845 X}$ & LN999 & LN999 \\
\hline 54 & $a$ & $a$ & E & onia & 910 & $\begin{array}{l}\mathrm{XX} \\
\mathrm{MF} 42 \\
\end{array}$ & $\begin{array}{l}\mathrm{XX} \\
\text { MF42 } \\
\end{array}$ & $\begin{array}{l}\text { XX } \\
\text { MF53 }\end{array}$ & 916 & 928 \\
\hline $\mathrm{AM}$ & Echinophyll & orpheensi & & Austra & LN999 & $\underline{6140} \times$ & $\underline{6057 X}$ & $\underline{9848 X}$ & LN999 & LN999 \\
\hline $\begin{array}{l}6813 \\
\text { UNI }\end{array}$ & ia & $s$ & $\mathrm{~F}$ & lia & 911 & XX & XX & XX & 918 & 930 \\
\hline MIB & & & & French & & MF42 & MF42 & MF53 & & \\
\hline GA07 & Echinophyll & & & Polyne & HF954 & $\underline{6142 X}$ & $\underline{6059 x}$ & $\underline{9850} \times$ & LN999 & HF954 \\
\hline $\begin{array}{l}1 \\
\mathrm{UNI}\end{array}$ & ia & tarae & $\mathrm{F}$ & $\begin{array}{l}\text { sia } \\
\text { Gulf }\end{array}$ & 229 & $\begin{array}{l}\overline{X X} \\
\text { MF42 }\end{array}$ & $\overline{X X}$ & $\begin{array}{l}\overline{X X} \\
\text { MF53 }\end{array}$ & 919 & 317 \\
\hline MIB & Echinophyll & & & of & HE654 & $\overline{6141 X}$ & MF42 & $\overline{9849} \times$ & LK022 & HE648 \\
\hline BA00 & ia & aspera & $\mathrm{F}$ & Aden, & 648 & $\overline{X X}$ & $\overline{6058}$ & $\overline{X X}$ & 412 & 564 \\
\hline
\end{tabular}


$\mathrm{MNH}$

N IK-

2012-

14230

IRD

HS32

74

UNI

MIB

PFB1

89

UNI

MIB

PFB0

47

$\mathrm{MNH}$

N IK-

2012-

14234

IRD

HS32

78

IRD

HS3 1

72

UNI

MIB

PFB7

26

KAU

ST

SA12

94

KAU

ST

SA04

73

WA

$\mathrm{M}$

Z657

85

UNI

MIB

GA02

4

UNI

MIB

MY3

25

IRD

HS31

18

IRD

HS31

35

UNI

MIB

BA10

7
IRD
Echinophy

$$
\text { ia }
$$

Echinophy

ia glabra F

Echinophyll echinopor

ia

Echinophyll

Echinophyll

ia

Oxypora echinata G

Oxypora lacera $\quad$ G

Ora

Oxypor

crassispin

Oxypora convoluta G

Oxypora

Cynarina lacrymalis $\mathrm{H}$

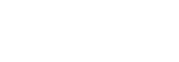

Lobophyllia

rowleyens

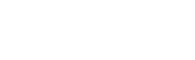

Lobophyllia costata I

Lobophyllia diminuta I

Lobophylli

valencien
Lobophyllia

$\begin{array}{lll}\text { Lobophyllia } & \text { radians } & \text { I } \\ \text { Lobophyllia } & \text { hishigakie } & \text { I }\end{array}$ n

\begin{tabular}{|c|c|c|c|c|c|c|}
\hline $\begin{array}{l}\text { Maldi } \\
\text { ves }\end{array}$ & $\begin{array}{l}\text { Arrigo } \\
\text { ni et al. } \\
\text { (2016) }\end{array}$ & $\frac{\text { MF42 }}{\frac{6145 X}{X X}}$ & $\frac{\text { MF42 }}{\frac{6087 X}{X X}}$ & $\frac{\frac{\text { MF53 }}{9877 X}}{X X}$ & $\begin{array}{l}\text { Arrigon } \\
\text { i et al. } \\
\text { (2016) }\end{array}$ & $\begin{array}{l}\text { Arrigo } \\
\text { ni et al. } \\
\text { (2016) }\end{array}$ \\
\hline New & & MF42 & MF42 & $\underline{\text { MF53 }}$ & & \\
\hline Caled & HF954 & 6144X & $\overline{6061 X}$ & $9852 X$ & LN999 & HF954 \\
\hline $\begin{array}{l}\text { onia } \\
\text { Papua }\end{array}$ & 225 & $\overline{\mathrm{XX}}$ & $\overline{\mathrm{XX}}$ & $\overline{\mathrm{XX}}$ & 927 & 313 \\
\hline New & & MF42 & MF42 & MF53 & & \\
\hline Guine & HF954 & $\overline{6143 X}$ & $\overline{6060 X}$ & $\overline{9851 X}$ & LK022 & HF954 \\
\hline $\begin{array}{l}\text { a } \\
\text { Papua }\end{array}$ & 235 & $\overline{X X}$ & $\overline{X X}$ & $\overline{X X}$ & 413 & 323 \\
\hline New & MF426 & MF42 & MF42 & MF53 & MF426 & MF426 \\
\hline $\begin{array}{l}\text { Guine } \\
\text { a }\end{array}$ & $\frac{205 X X}{X}$ & $\frac{6146}{X X}$ & $\frac{6094 X}{X X}$ & $\frac{9884 X}{X X}$ & $\frac{128}{X} X X$ & $\frac{109}{X} X X$ \\
\hline
\end{tabular}

Red

Sea, Arrigo MF42 $\underline{\text { MF42 }} \underline{\text { MF53 }}$ Arrigon Arrigo

Saudi ni et al. $\quad \underline{6190 \times} \quad \underline{6088} \times \quad \underline{9878} \times \quad$ i et al. ni et al.

$\begin{array}{lllllll}\text { Arabia (2016) } & \mathbf{X X} & \mathbf{X X} & \mathbf{X X} & \text { (2016) } & \text { (2016) }\end{array}$

New $\underline{\text { MF42 }} \quad \underline{\text { MF42 }} \quad \underline{\text { MF53 }}$

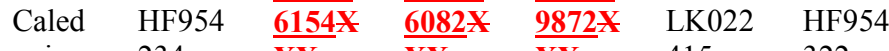

$\begin{array}{lllllll}\text { onia } & 234 & \mathbf{X X} & \mathbf{X X} & \mathbf{X X} & 415 & 322\end{array}$

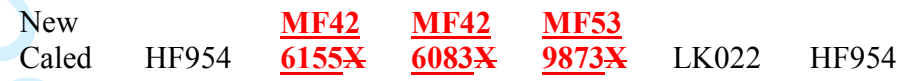

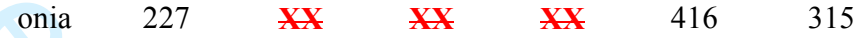

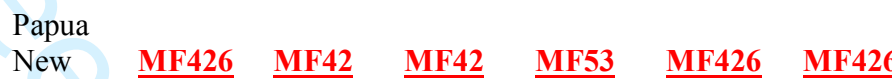

Guine $\quad \frac{206}{\mathrm{X} X} \quad \frac{6176 \mathrm{X}}{\mathrm{XX}} \quad \frac{6093 \mathrm{X}}{\mathrm{XX}} \quad \frac{9883 \mathrm{X}}{\mathrm{XX}} \quad \frac{129 X X}{\mathrm{X}} \quad \frac{110 X X}{\mathrm{X}}$

Red

Sea, $\quad \underline{\text { MF42 }} \quad$ MF42 $\quad$ MF53

$\begin{array}{lllllll}\text { Saudi } & \text { LN999 } & \underline{\mathbf{6 1 5 6 X}} & \underline{\mathbf{6 0 8 4 X}} & \underline{\mathbf{9 8 7 4 X}} & \text { LN999 } & \text { LN999 }\end{array}$

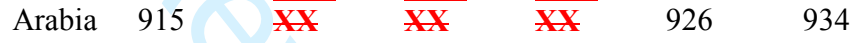

Red

Sea, $\underline{\text { MF42 }} \underline{\text { MF42 }} \underline{\text { MF53 }}$

$\begin{array}{lllllll}\text { Saudi } & \text { LM993 } & \underline{\mathbf{6 1 3 9}} & \underline{\mathbf{6 0 5 6}} & \underline{\mathbf{9 8 4 7 X}} & \text { LM993 } & \text { LN999 }\end{array}$

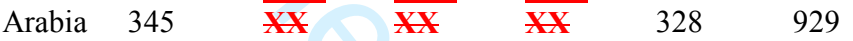

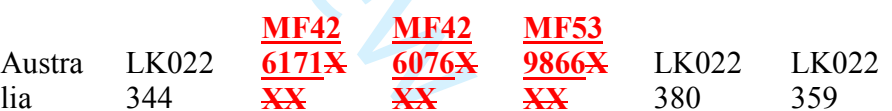

French $\quad$ MF42 $\quad$ MF42 $\quad \underline{\text { MF53 }}$

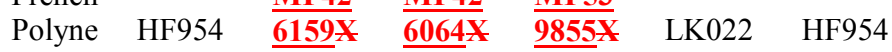

$\begin{array}{lllllll}\text { sia } 246 & \mathbf{X X} & \mathbf{X X} & \mathbf{X X} & 421 & 333\end{array}$

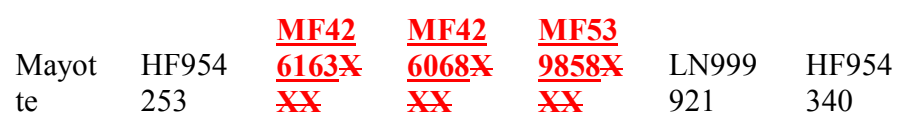

$\begin{array}{lllllll}\text { New } & & \underline{\text { MF42 }} & \underline{\text { MF42 }} & \underline{\text { MF53 }} & & \\ \text { Caled } & \text { HF954 } & \underline{\mathbf{6 1 6 0 X}} & \underline{\mathbf{6 0 6 5 X}} & \underline{\mathbf{9 8 5 6}} & \text { LK022 } & \text { HF954 }\end{array}$

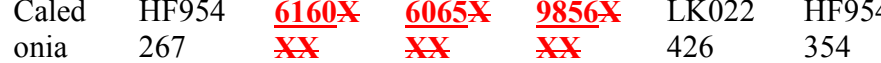

$\begin{array}{lllllll}\text { New } & & \underline{\text { MF42 }} & \underline{\text { MF42 }} & \underline{\text { MF53 }} & & \\ \text { Caled } & \text { HF954 } & \underline{\mathbf{6 1 6 1 X}} & \underline{\mathbf{6 0 6 6 X}} & \underline{\mathbf{9 8 5 7 X}} & \text { LK022 } & \text { HF954 }\end{array}$

$\begin{array}{lllllll}\text { onia } & 260 & \frac{\mathbf{X X}}{\mathbf{X X}} & \frac{\mathbf{6 0 6 6}}{\mathbf{X X}} & \frac{\mathbf{9 8 5 7}}{\mathbf{X X}} & 427 & 347\end{array}$

$\begin{array}{lllllll}\text { New } & & \underline{\text { MF42 }} & \underline{\text { MF42 }} & \underline{\text { MF53 }} & & \\ \text { Caled } & \text { HE654 } & \underline{\mathbf{6 1 6 2}} & \underline{\mathbf{6 0 6 7 X}} & \underline{\mathbf{9 8 5 5}} & \text { LK022 } & \text { HE648 } \\ \text { onia } & 644 & \underline{\text { XX }} & \underline{\text { XX }} & \underline{\text { XX }} & 425 & 560 \\ \text { New } & \underline{\text { MF426 }} & \underline{\text { MF42 }} & \underline{\text { MF42 }} & \underline{\text { MF53 }} & \underline{\text { MF426 }} & \underline{\text { MF426 }}\end{array}$




\begin{tabular}{|c|c|c|c|c|c|c|c|c|c|c|}
\hline $\begin{array}{l}\text { HS33 } \\
58\end{array}$ & & nsis & & $\begin{array}{l}\text { Caled } \\
\text { onia }\end{array}$ & $\frac{207 X X}{X}$ & $\frac{6174 X}{X X}$ & $\frac{6091 X}{X X}$ & $\frac{9881 X}{X X}$ & $\frac{130 X X}{X}$ & $\frac{111 X X}{X}$ \\
\hline UNI & & & & & & & & & & \\
\hline MIB & & & & New & & $\underline{\text { MF42 }}$ & $\underline{\text { MF42 }}$ & $\underline{\text { MF53 }}$ & & \\
\hline PFB0 & & & & Guine & LK022 & $\underline{6164 X}$ & $\underline{6069} \times$ & $\underline{9859} \times$ & LK022 & LK022 \\
\hline 52 & Lobophyllia & vitiensis & I & $\mathrm{a}$ & 355 & XX & XX & XX & 394. & 373 \\
\hline UNI & & & & Papua & & & & & & \\
\hline MIB & & & & New & & MF42 & MF42 & MF53 & & \\
\hline PFB1 & & flabellifor & & Guine & HF954 & $\underline{6165 X}$ & $\underline{6070 X} \times$ & $\underline{9860 x}$ & LN999 & HF954 \\
\hline 03 & Lobophyllia & mis & I & a & 248 & $\overline{\mathbf{X X}}$ & $\overline{X X}$ & $\overline{\mathrm{XX}}$ & 923 & 335 \\
\hline UNI & & & & Papua & & & & & & \\
\hline MIB & & & & New & & MF42 & MF42 & $\underline{\text { MF53 }}$ & & \\
\hline PFB1 & & & & Guine & HF954 & $\underline{6166} \times$ & $\underline{6071 X}$ & $\underline{9861 X}$ & LK022 & HF954 \\
\hline 04 & Lobophyllia & agaricia & I & $\mathrm{a}$ & 263 & $\overline{X X}$ & $\overline{X X}$ & $\overline{X X}$ & 424 & 350 \\
\hline UNI & & & & Papua & & & & & & \\
\hline MIB & & & & New & & MF42 & MF42 & MF53 & & \\
\hline PFB1 & & & & Guine & HF954 & $\overline{6167 X}$ & $\overline{6072 X}$ & $\overline{9862 X}$ & LK022 & HF954 \\
\hline 83 & Lobophyllia & robusta & I & $\mathrm{a}$ & 250 & $\overline{X X}$ & $\overline{X X}$ & $\overline{X X}$ & 423 & 337 \\
\hline UNI & & & & Papua & & & & & & \\
\hline MIB & & & & New & $\underline{\text { MF426 }}$ & MF42 & $\underline{\text { MF42 }}$ & MF53 & $\underline{\text { MF426 }}$ & $\underline{\text { MF426 }}$ \\
\hline PFB7 & & & & Guine & $\underline{208} X X$ & $\underline{6172 X}$ & $\underline{6089 x}$ & $\underline{9879 \times}$ & $\underline{131 X X}$ & $\underline{112 X X}$ \\
\hline 83 & Lobophyllia & hassi & I & $\begin{array}{l}\text { a } \\
\text { Panua }\end{array}$ & $\bar{x}$ & $\overline{X X}$ & $\overline{\mathrm{XX}}$ & $\overline{X X}$ & $\bar{x}$ & $\bar{x}$ \\
\hline MIB & & & & New & MF426 & MF42 & MF42 & $\underline{\text { MF53 }}$ & MF426 & MF426 \\
\hline PFB7 & & & & Guine & $\overline{209 \times X}$ & $\overline{6173 x}$ & $\overline{6090 x}$ & $\overline{\mathbf{9 8 8 0} X}$ & $\overline{132 X X}$ & $\overline{113 X X}$ \\
\hline 97 & Lobophyllia & hataii & I & $\mathrm{a}$ & $\mathbf{X}$ & XX & $\mathbf{X X}$ & XX & $\mathrm{X}$ & $\mathrm{X}$ \\
\hline KAU & & & & Red & & & & & & \\
\hline ST & & & & Sea, & & $\underline{\text { MF42 }}$ & MF42 & $\underline{\text { MF53 }}$ & & \\
\hline SA03 & & & & Saudi & LN999 & $\overline{6168 x}$ & $\overline{6073} x$ & $\overline{9863 X}$ & LN999 & LN999 \\
\hline 65 & Lobophyllia & erythraea & I & Arabia & 913 & $\overline{X X}$ & $\overline{X X}$ & $\overline{X X}$ & 922 & 932 \\
\hline KAU & & & & Red & & & & & & \\
\hline ST & & & & Sea, & & MF42 & MF42 & $\underline{\text { MF53 }}$ & & \\
\hline SA03 & & corymbos & & Saudi & LN999 & $\overline{6169 x}$ & $\overline{6074 X}$ & $\overline{9864 X}$ & LN999 & LN999 \\
\hline $\begin{array}{l}77 \\
\text { KAU }\end{array}$ & Lobophyllia & $a$ & I & $\begin{array}{l}\text { Arabia } \\
\text { Red }\end{array}$ & 912 & $\overline{X X}$ & $\overline{\mathrm{XX}}$ & $\overline{X X}$ & 920 & 931 \\
\hline ST & & & & Sea, & & MF42 & MF42 & MF53 & & \\
\hline SA04 & & hemprichi & & Saudi & LN999 & $6170 x$ & $\overline{6075 x}$ & $\overline{9865 X}$ & LN999 & LN999 \\
\hline 51 & Lobophyllia & $i$ & I & Arabia & 914 & $\overline{X X}$ & $\overline{X X}$ & $\overline{\mathrm{XX}}$ & 924 & 933 \\
\hline $\mathrm{AM}$ & & & & & & MF42 & MF42 & MF53 & & \\
\hline WIL0 & Australophy & & & Austra & LN875 & $\overline{6138 x}$ & $\overline{6055 X}$ & $\overline{9846 x}$ & LN875 & LN876 \\
\hline \multirow[t]{3}{*}{2} & llia & wilsoni & $\mathrm{J}$ & lia & 915 & $\overline{\mathrm{XX}}$ & $\overline{\mathbf{X X}}$ & $\overline{\mathrm{XX}}$ & 994 & 071 \\
\hline & & & outgro & & AP008 & AP008 & AP008 & AP008 & HQ203 & HQ203 \\
\hline & Orbicella & annularis & up & & 974 & 974 & 974 & 974 & 600 & 367 \\
\hline
\end{tabular}


Table 2

Primer information and gene statistics for each locus used in the analysis. Number of sites (S), Number of variable sites (\%) (SV), Number of parsimony-informative sites (\%) (SPI), Haplotype diversity (HD), Nucleotide diversity

(ND), GC-content (GC), , best fit model of molecular evolution (M)

\begin{tabular}{|c|c|c|c|c|c|c|c|c|}
\hline Locus & Primers & Reference & $\mathrm{S}$ & SV & SPI & $\mathrm{HD}$ & ND & GC \\
\hline $\mathrm{COI}$ & $\begin{array}{l}\text { MCOIF- } \\
\text { MCOIR }\end{array}$ & $\begin{array}{l}\text { Fukami et } \\
\text { al. (2004) }\end{array}$ & 628 & $\begin{array}{l}65 \\
(10.3 \%)\end{array}$ & $40(6.3 \%)$ & $\begin{array}{l}0.95 \pm \\
0.02\end{array}$ & $\begin{array}{l}0.02 \pm \\
0.01\end{array}$ & 37.1 \\
\hline $12 \mathrm{~S}$ & $\begin{array}{l}\text { ANTMT12SF- } \\
\text { ANTMT12SR }\end{array}$ & $\begin{array}{l}\text { Chen and } \\
\text { Yu (2000) }\end{array}$ & 694 & $55(7.9 \%)$ & $37(5.3 \%)$ & $\begin{array}{l}0.94 \pm \\
0.01\end{array}$ & $\begin{array}{l}0.02 \pm \\
0.01\end{array}$ & 34.1 \\
\hline $\begin{array}{l}\text { ATP6- } \\
\text { NAD4 }\end{array}$ & RSF6-RSR6 & $\begin{array}{l}\text { Lin et al. } \\
\text { (2011) }\end{array}$ & 825 & $\begin{array}{l}131 \\
(15.8 \%)\end{array}$ & $\begin{array}{l}104 \\
(12.6 \%)\end{array}$ & $\begin{array}{l}0.94 \pm \\
0.01\end{array}$ & $\begin{array}{l}0.02 \pm \\
0.01\end{array}$ & 33.7 \\
\hline $\begin{array}{l}\text { NAD3- } \\
\text { NAD5 }\end{array}$ & RSF13-RSR13 & $\begin{array}{l}\text { Lin et al. } \\
\text { (2011) }\end{array}$ & 844 & $57(6.7 \%)$ & $35(4.1 \%)$ & $\begin{array}{l}0.93 \pm \\
0.01\end{array}$ & $\begin{array}{l}0.01 \pm \\
0.01\end{array}$ & 31.3 \\
\hline $\begin{array}{l}\text { Histone } \\
\mathrm{H} 3\end{array}$ & H3F-H3R & $\begin{array}{l}\text { Colgan et } \\
\text { al. (1998) }\end{array}$ & 317 & $\begin{array}{l}75 \\
(23.6 \%)\end{array}$ & $\begin{array}{l}70 \\
(22.1 \%)\end{array}$ & $\begin{array}{l}0.89 \pm \\
0.03\end{array}$ & $\begin{array}{l}0.05 \pm \\
0.02\end{array}$ & 52.5 \\
\hline ITS & A18S-ITS4 & $\begin{array}{l}\text { White et al. } \\
(1990) \text {, } \\
\text { Takabayashi } \\
\text { et al. (1998) }\end{array}$ & 652 & $\begin{array}{l}255 \\
(39.7 \%)\end{array}$ & $\begin{array}{l}209 \\
(32.2 \%)\end{array}$ & $\begin{array}{l}0.99 \pm \\
0.01\end{array}$ & $\begin{array}{l}0.09 \pm \\
0.03\end{array}$ & 56.2 \\
\hline
\end{tabular}

Formatted Table 
Table 3

Pairwise comparisons of genetic distance values (p-distance) within and between genera of Lobophylliidae based on the combined dataset (COI, 12S, ATP6-NAD4, NAD3-NAD5, Histone H3, ITS). Intergeneric pairwise comparisons of genetic distance are in bold, intrageneric genetic distances are indicated along the diagonal, and standard deviations are reported either in brackets or on the upper right hand portions for each set of comparisons. n.c. $=$ not calculable

\begin{tabular}{|c|c|c|c|c|c|c|c|c|c|c|c|}
\hline & $\begin{array}{l}\text { Micromu } \\
\text { ssa }\end{array}$ & $\begin{array}{l}\text { Homo } \\
\text { phyllia }\end{array}$ & $\begin{array}{l}\text { Sclero } \\
\text { phyllia }\end{array}$ & $\begin{array}{l}\text { Mos } \\
\text { eleya }\end{array}$ & $\begin{array}{l}\text { Acanth } \\
\text { astrea }\end{array}$ & $\begin{array}{l}\text { Echino } \\
\text { phyllia }\end{array}$ & $\begin{array}{l}\text { Oxуро } \\
\text { ra }\end{array}$ & $\begin{array}{l}\text { Cynarin } \\
a\end{array}$ & $\begin{array}{l}\frac{\text { Loboph }}{\text { ylliaAus }} \\
\text { ylliat } \\
\text { y }\end{array}$ & $\begin{array}{l}\text { Austral } \\
\text { ophyllia }\end{array}$ & 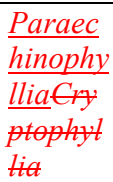 \\
\hline $\begin{array}{l}\text { Micromu } \\
\text { ssa }\end{array}$ & $\begin{array}{l}0.57 \\
(0.08)\end{array}$ & 0.25 & 0.28 & 0.30 & 0.25 & 0.30 & 0.37 & 0.28 & 0.30 & 0.21 & 0.28 \\
\hline $\begin{array}{l}\text { Homoph } \\
\text { yllia }\end{array}$ & 2.14 & $\begin{array}{l}0.71 \\
(0.14)\end{array}$ & 0.29 & 0.31 & 0.28 & 0.27 & 0.36 & 0.28 & 0.29 & 0.22 & 0.29 \\
\hline $\begin{array}{l}\text { Scleroph } \\
\text { yllia }\end{array}$ & 4.59 & 4.63 & $\begin{array}{l}0.03 \\
(0.03)\end{array}$ & 0.24 & 0.25 & 0.25 & 0.31 & 0.22 & 0.21 & 0.29 & 0.24 \\
\hline $\begin{array}{l}\text { Moseley } \\
a\end{array}$ & 4.54 & 4.54 & 2.72 & n.c. & 0.28 & 0.24 & 0.27 & 0.25 & 0.25 & 0.33 & 0.20 \\
\hline $\begin{array}{l}\text { Acanthas } \\
\text { trea }\end{array}$ & 4.41 & 4.42 & 3.46 & 3.10 & $\begin{array}{l}0.37 \\
(0.07)\end{array}$ & 0.27 & 0.28 & 0.26 & 0.25 & 0.29 & 0.25 \\
\hline $\begin{array}{l}\text { Echinop } \\
\text { hyllia }\end{array}$ & 5.28 & 5.27 & 3.41 & 2.51 & 3.53 & $\begin{array}{l}0.41 \\
(0.06)\end{array}$ & 0.26 & 0.26 & 0.23 & 0.30 & 0.24 \\
\hline Oxypora & 6.13 & 6.25 & 4.43 & 3.26 & 4.02 & 2.89 & $\begin{array}{l}0.27 \\
(0.05)\end{array}$ & 0.31 & 0.25 & 0.39 & 0.31 \\
\hline $\begin{array}{l}\text { Cynarin } \\
a\end{array}$ & 4.66 & 4.69 & 2.26 & 2.44 & 3.05 & 3.12 & 4.03 & n.c. & 0.21 & 0.31 & 0.19 \\
\hline $\begin{array}{l}\text { Lobophy } \\
\text { llia }\end{array}$ & 4.87 & 4.90 & 2.93 & 2.58 & 3.01 & 2.66 & 3.63 & 2.41 & $\begin{array}{l}0.58 \\
(0.07)\end{array}$ & 0.31 & 0.22 \\
\hline $\begin{array}{l}\text { Australo } \\
\text { phyllia }\end{array}$ & 2.01 & 2.10 & 4.40 & 4.42 & 4.44 & 5.11 & 6.06 & 4.54 & 4.75 & n.c. & 0.29 \\
\hline$\frac{\text { Paraechi }}{\text { nophylli }}$ & 4.42 & 4.63 & 2.71 & 2.35 & 3.27 & 2.68 & 3.45 & 2.77 & 2.63 & 4.44 & $\begin{array}{l}0.10 \\
(0.03)\end{array}$ \\
\hline
\end{tabular}


Table 4

Estimated divergence times (Ma) with 95\% highest posterior density (HPD) distribution for genera of Lobophylliidae and for some main nodes of the molecular phylogeny shown in Fig. 4. The posterior probabilities $(\mathrm{pp}) \geq 0.70$ obtained in BEAST are reported

\begin{tabular}{|c|c|c|c|}
\hline Taxon (Clade) & Node & Age in $\mathrm{Ma}(95 \% \mathrm{HPD})$ & $\mathrm{pp}$ \\
\hline Paraechinophyllia Crytophyllia (K) & II & $\underline{3.29 .2(1.2-6.45 .3-16.4)}$ & 1 \\
\hline Echinophyllia $(\mathrm{F})$ & III & $\underline{5.3} 15.1(\underline{2.3-9.58 .323 .5)}$ & 1 \\
\hline Oxypora $(\mathrm{G})$ & IV & $\underline{3.1} 8.8(\underline{1.6-5.34} 4.9-15.2)$ & 1 \\
\hline Echinophyllia/Oxypora (F vs. G) & $\mathrm{V}$ & $\underline{13.7} 31.4(\underline{6.3-22.912 .750 .3)}$ & 1 \\
\hline Paraechinophyllia Eryptophyllia vs. & VI & $\underline{21.5} 45.4(\underline{11.6-33.725-71.1)}$ & 1 \\
\hline \multicolumn{4}{|l|}{ Echinophyllia/Oxypora (K vs. F-G) } \\
\hline Micromussa (A) & VII & $\underline{8.22} z 1.1(\underline{3.4-14.8} 10.7-32.5)$ & 1 \\
\hline Homophyllia (B) & VIII & $\underline{4.7} 12.8(\underline{1.9-9.7} 6.5-24.4)$ & 1 \\
\hline Australophyllia vs. & IX & $\underline{20.3} 45.2(\underline{11.2-33.626 .4-66.8})$ & 1 \\
\hline \multicolumn{4}{|l|}{ Micromussa/Homophyllia (J vs. A-B) } \\
\hline Acanthastrea (E) & $X$ & $\underline{412.4}(\underline{1.5-8.16 .526 .1)}$ & 1 \\
\hline Sclerophyllia $(\mathrm{C})$ & XI & $\underline{0.72 .1}(\underline{0.1-2.10 .25 .4)}$ & 1 \\
\hline Sclerophyllia vs. Moseleya (C vs. D) & XII & $\underline{21.2} 42.8(\underline{12.4-32.1} 18.9-72.5)$ & 1 \\
\hline Lobophyllia-vs. Cynarina (I-vs. H) & XIII & $\underline{8.446 .4}(\underline{5.8-13.426 .9-67.1)}$ & 1 \\
\hline
\end{tabular}



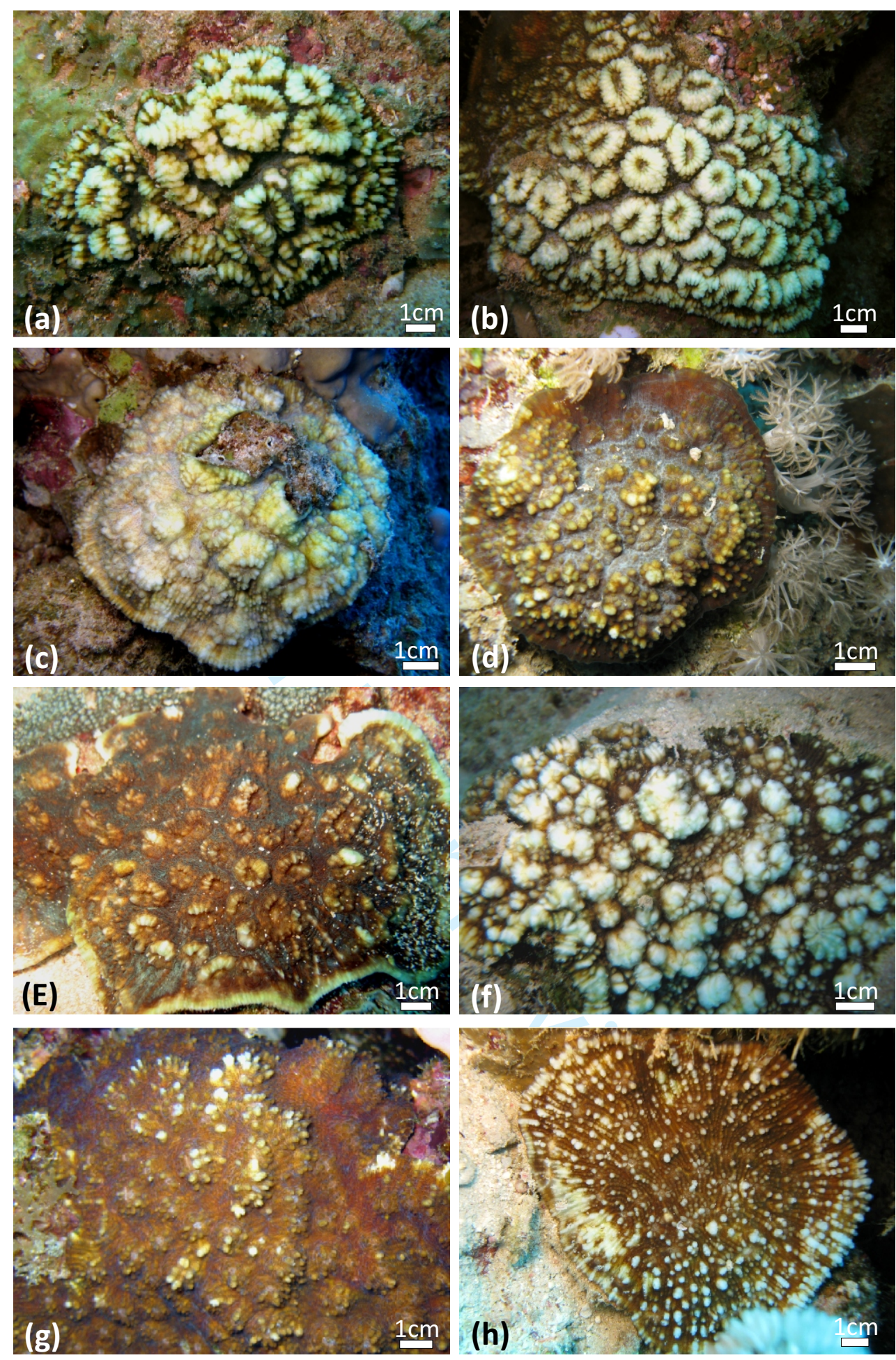

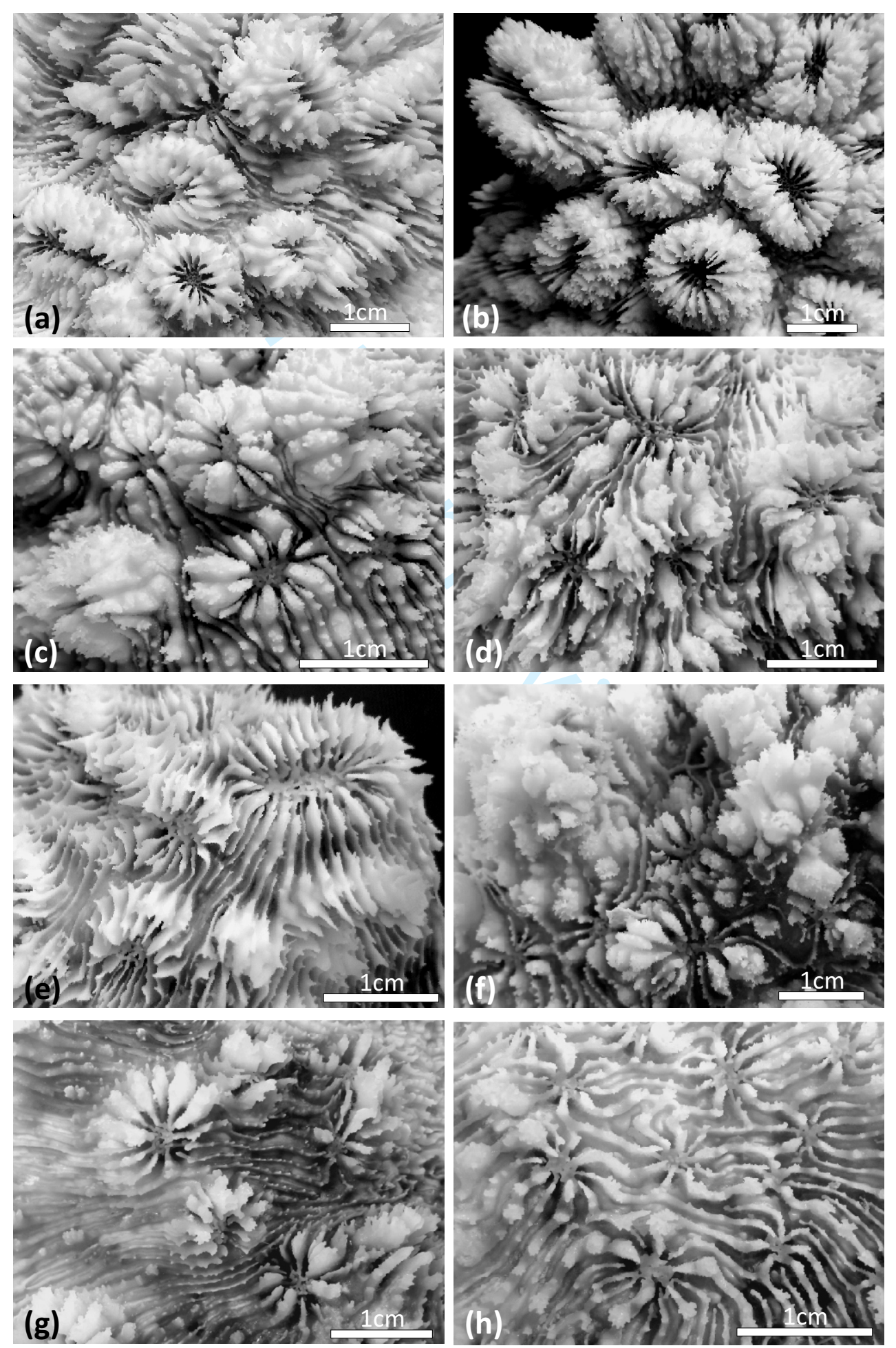

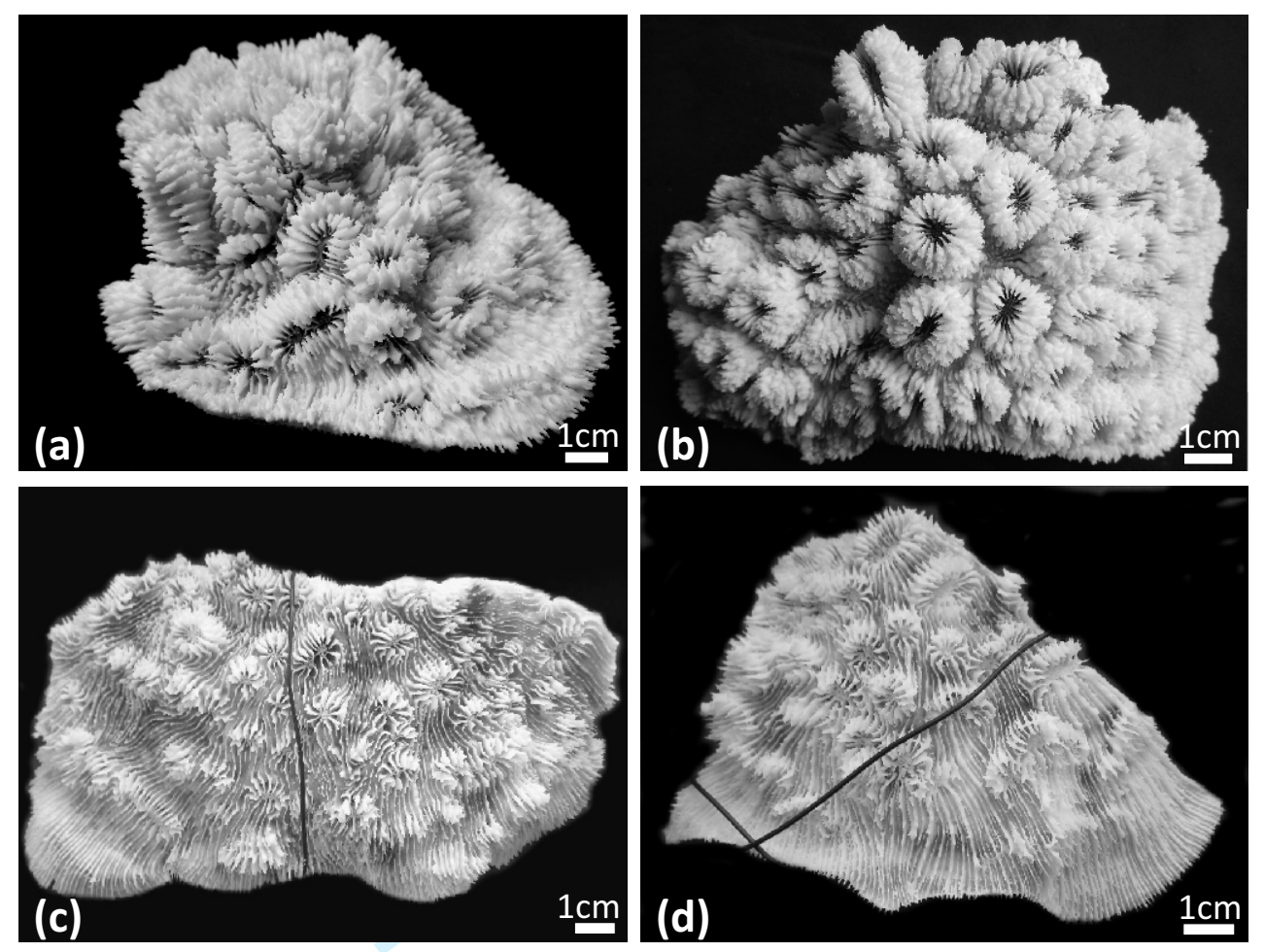

25

26

27

28

29

30

31

32

33

34

35

36

37

38

39

40

41

42

43

44

45

46

47

48

49

50

51

52

53

54

55

56

57

58

59

60 


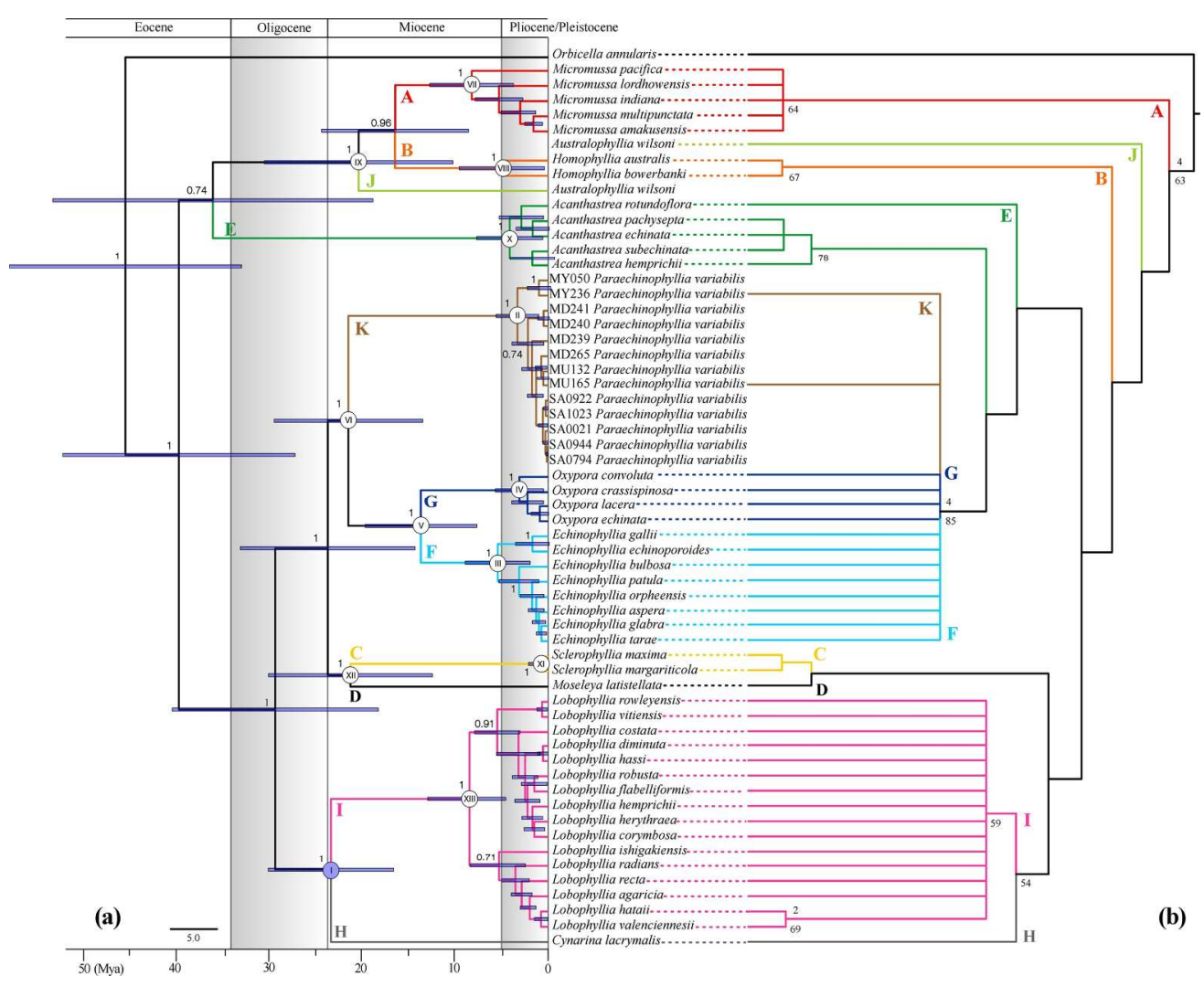

Fig. 4. Phylogeny reconstruction of the family Lobophylliidae, showing the position of Paraechinophyllia variabilis gen. et sp. nov (clade K). (a) Multi-locus time-calibrated phylogeny reconstruction inferred from the concatenated dataset (COI, 12S, ATP6-NAD4, NAD3-NAD5, histone H3, and ITS, 3965 bp), analysed using BEAST. The violet circle I marks the node that was time-constrained with fossil (the stratigraphically oldest fossil occurrence of Lobophyllia, 19-31.3 Mya) as described in the text. Node values are posterior probabilities ( $\geq 0.7$ ) and violet bars display the $95 \%$ highest posterior density (HPD) interval of node ages. (b) Strict consensus of 19 maximum parsimony trees based on 46 morphological characters, analysed using TNT. Values above nodes are Bremer decay index $(\geq 2)$ and below nodes are maximum parsimony bootstrap ( $\geq 50$ ). Clades from A to J are labelled and coloured according to Arrigoni et al. (2014a) and Huang et al. (2016).

$197 \times 158 \mathrm{~mm}(300 \times 300$ DPI $)$ 

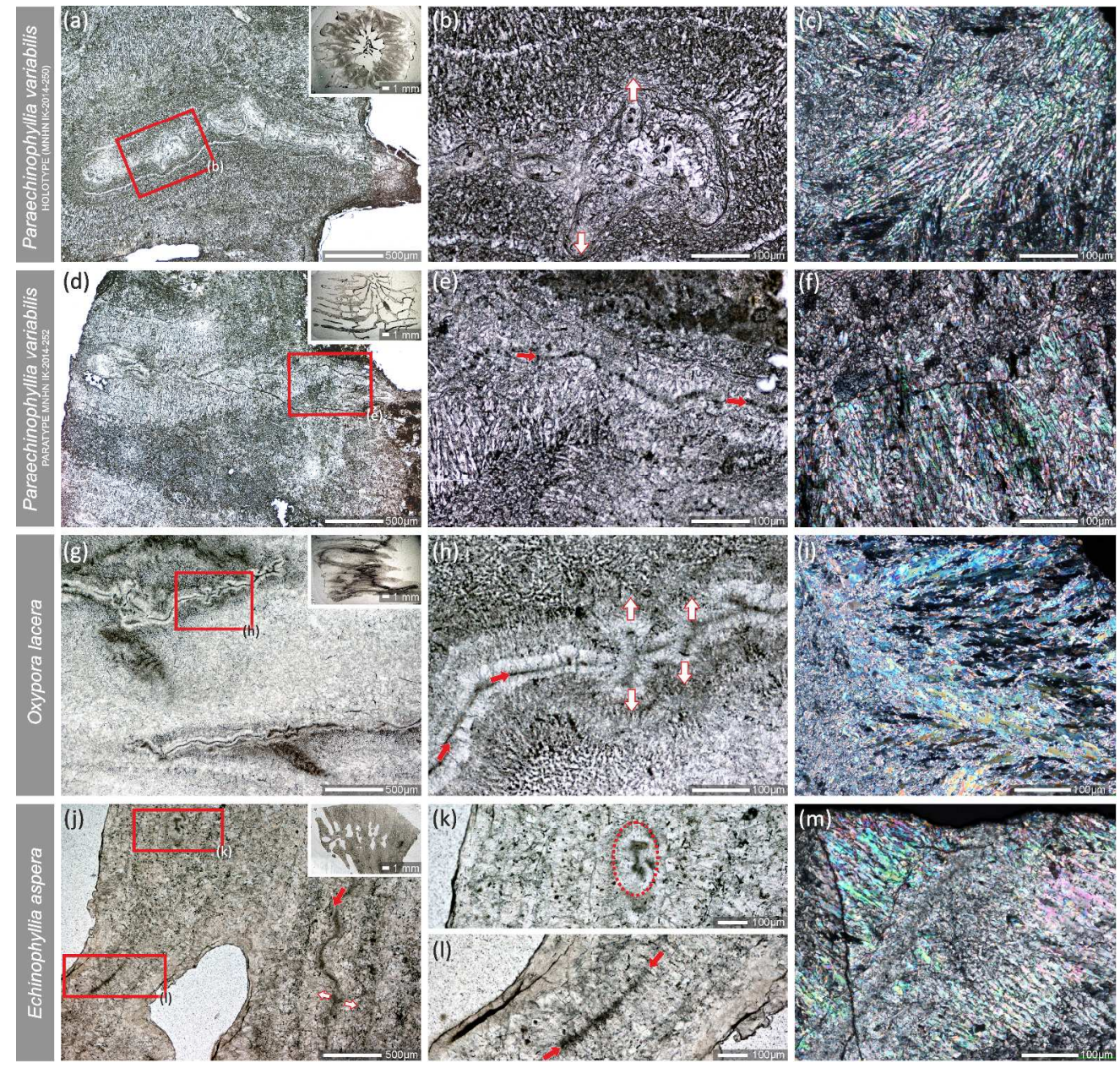

Fig. 5. Microstructural characteristics of Paraechinophyllia variabilis gen. et sp. nov. robust morphotype MNHN IK-2014-250 (a-c) and less robust MNHN IK-2014-252 (d-f) in direct comparison to Oxypora (O. lacera, g-i) and Echinophyllia (E. aspera, j-m); optical transmitted light microscopy (insets in right-upper corners of $a, d, g, j$ show low magnification images of sections). In more robust coralla of MNHN IK-2014-250 lower order septa show clusters of Rapid Accretion Deposits (RAD's) with projections extending toward the septal faces (red outlined white arrows in $b$ ). Such lateral projections of RAD's can also be observed in lower order septa of less robust $O$. lacera and $E$. aspera $(\mathrm{h}, \mathrm{k})$. Septa of less robust MNHN IK-2014-252 and higher order septa of $O$. lacera and $E$. aspera have RAD's frequently in a form of straight or wavy mid-septal zone (red arrows, see e, $h, j, l$ ). Sectioned septal teeth show elliptical clusters of RAD's (dashed red outline in $k$ ). Thickening deposits (TD's) consists of well delineated, slender (typically longer than $100 \mu \mathrm{m}$ ) bundles of fibers, ca. $10 \mu \mathrm{m}$ in diameter (c, i, m, polarized light). Thickness of fibre boundless is consistent with diameter of microtuberculate texture on septal faces (compare Fig. 6i, 7g). 

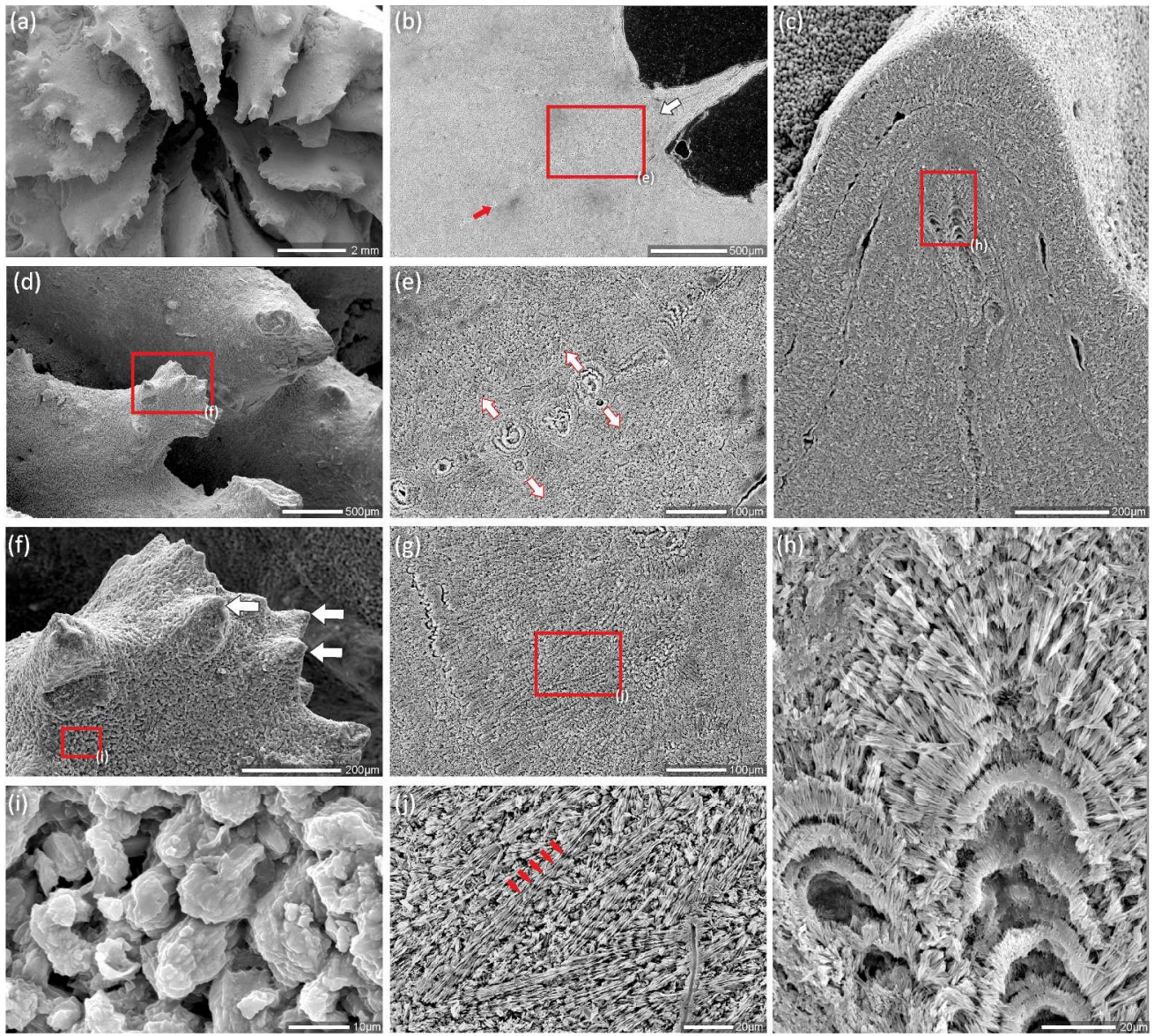

Fig. 6. Microstructural characteristics of robust morphotype of Paraechinophyllia variabilis gen. et sp. nov. (MNHN IK-2014-250) in SEM: natural surfaces ( $a, d, f, i)$ and polished and delicately etched sections (b, $c$, $e, g, h, j$ ). Distinct tooth show several RAD's regions ( $d, f$, white arrows). Septal faces (especially in distal region) are covered with microtuberculate texture ca. $10 \mu \mathrm{m}$ in diameter (i). Rapid Accretion Deposits (RAD's) in more robust septa (also within well differentiated septal teeth) form projections extending toward the septal faces (red outlined arrows in e), however between such regions RAD's typically form continuous mid-septal line (red arrow in b). TD's show regular growth banding (red arrows in $\mathrm{j}$ ). Mid-septal zone in longitudinal section of septum $(c, h)$. 

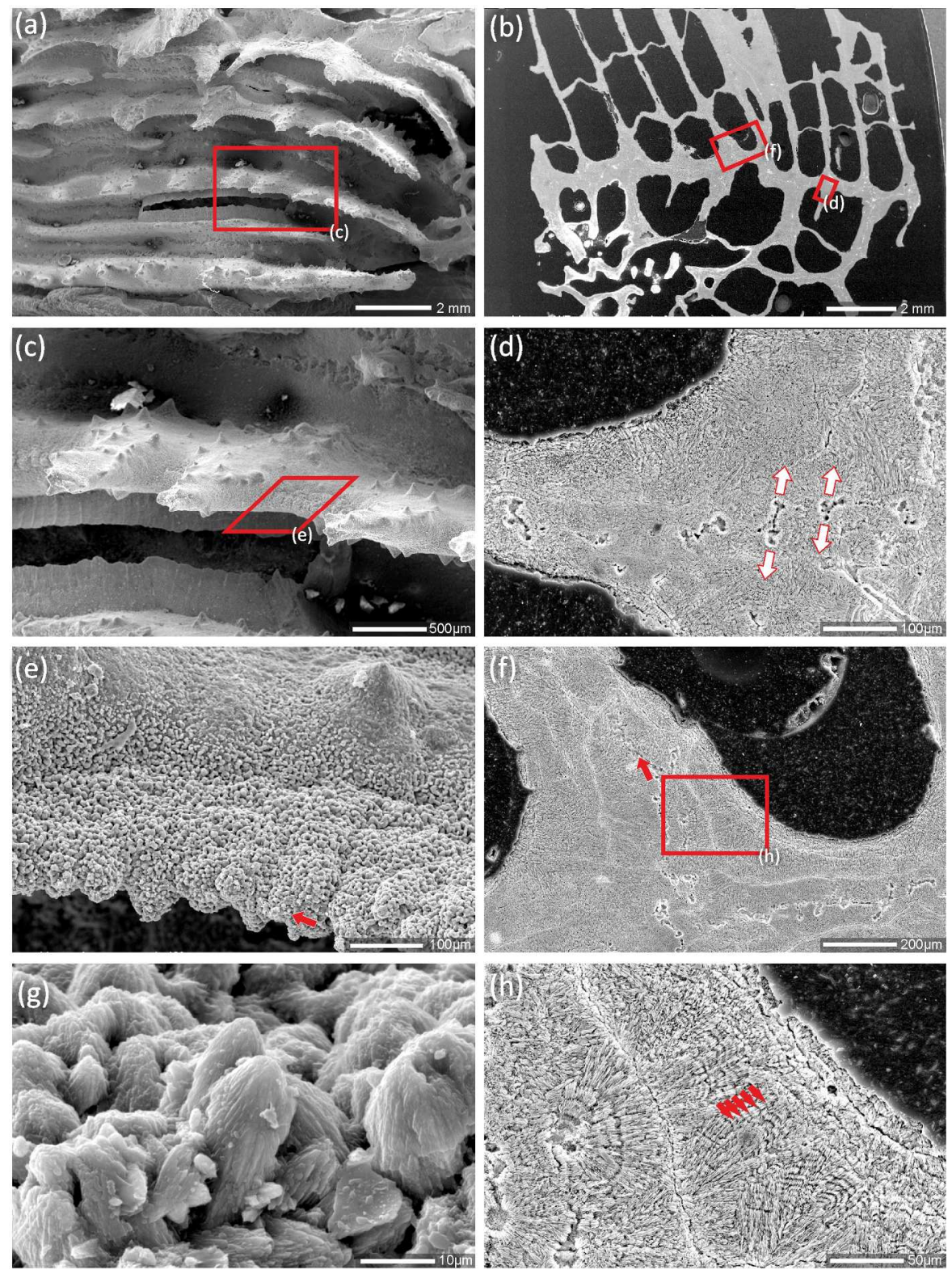

Fig. 7. Microstructural characteristics of less robust morphotype of Paraechinophyllia variabilis gen. et sp. nov. (MNHN IK-2014-252) in SEM: natural surfaces (a, c, e, g) and polished and delicately etched sections $(b, d, f, h)$. Distinct tooth on lower cycle septa show several RAD's regions (d, white arrows). Septal faces are covered with microtuberculate texture ca. $10 \mu \mathrm{m}$ in diameter (e, g). Rapid Accretion Deposits (RAD's) in less robust septa form continuous mid-septal line (red arrows in e, f), whereas in slightly more robust ones they form clusters with projections extending toward the septal faces as in robust morphotypes of $P$. variabilis (red outlined arrows in d). TD's show regular growth banding (red arrows in $h$ ).

$$
193 \times 260 \mathrm{~mm}(300 \times 300 \mathrm{DPI})
$$

